\title{
INTERNAL STRUCTURES OF KNOWN Pinctada maxima Pearls: Cultured Pearls from Operated Marine Mollusks
}

Artitaya Homkrajae, Nanthaporn Nilpetploy, Areeya Manustrong, Nicholas Sturman, Kwanreun Lawanwong, and Promlikit Kessrapong

Saltwater non-bead cultured pearls, sometimes referred to as "keshi," are byproducts of the bead cultured pearl cultivation process and are mainly composed of solid nacre, in keeping with natural pearls. They often form as individual pearls or may be seen as additional features on the surfaces of some bead cultured (BC) pearls, sometimes known as "Tokki pearls." The 86 saltwater cultured samples in this study, comprising 74 non-bead cultured (NBC) pearls and 12 BC pearls with intriguing additional surface features, were collected directly from the gonads of operated Pinctada maxima mollusks by two of the authors during a visit to a pearl farm. They were collected in order to study the internal structures using real-time microradiography and X-ray computed microtomography analyses. Three structural types-including organic-rich concentric, void, and linear-were observed in the NBC samples, as expected for saltwater NBC pearls produced by Pinctada species. The structures were also observed within the associated additional features related to the bead nuclei in the $\mathrm{BC}$ pearl samples. The internal features of most of the NBC samples permitted them to be separated from their natural counterparts. Nevertheless, a limited number of NBC samples contained particular structural forms similar to those observed in known P. maxima natural pearls previously studied, or they contained complex overlapping features that do not conform to the majority of structures observed in NBC pearls in this study and previous publications. This illustrates the challenges GIA and other gemological laboratories face with some pearl identification cases. Therefore, GIA's procedure in addressing such cases is discussed and demonstrated. Since the pearl identification stated on reports is an opinion based on a reference collection database and the gemologist's experience, possible differences of opinion among various gemologists and organizations are hardly surprising. This study on known cultured pearls provides additional reliable data that is essential in consolidating GIA's reference collection database on the internal structures of pearls.

P inctada maxima (the silver- or gold-lipped pearl oyster), Pinctada margaritifera (the blacklipped pearl oyster), and Pinctada fucata (martensii) ("the akoya pearl oyster") are the main mollusks of the Pinctada genus that are commercially farmed. They are routinely used to produce bead cultured $(\mathrm{BC})$ pearls and, as a consequence, sometimes also produce non-bead cultured (NBC) pearls (Otter et al., 2014; Sturman et al., 2016; Nilpetploy et al., 2018a). P. maxima is the largest species in the genus (Scarratt et al., 2012) and generally requires a minimum two-year growth period to yield $\mathrm{BC}$ pearls with the thickest nacre layers of all $\mathrm{BC}$ pearls

See end of article for About the Authors and Acknowledgments.

Gems \& Gemology, Vol. 57, No. 3, pp. 186-205,

http://dx.doi.org/10.5741/GEMS.57.3.186

(C) 2021 Gemological Institute of America
(Gervis and Sims, 1992; Cartier and Krzemnicki, 2016). Cultured pearls from the P. maxima mollusk are often referred to as "South Sea" in the market.

Australia is the largest producer of white P. maxima (silver-lipped) cultured pearls, while Indonesia, Myanmar, and the Philippines are major producers of "golden" P. maxima (gold-lipped) cultured pearls. The farms producing these pearls are located between the Tropic of Cancer and the Tropic of Capricorn, which coincides with the native $P$. maxima mollusk's geographic distribution. The silver-lipped shells are found mostly south of the equator, while the gold-lipped shells populate the region north of the equator (Strack, 2006). P. maxima mollusks used for pearl culturing production in Australia are predominantly wildcaught shells collected in accordance with the annual quota that takes the shell sizes into account (between 120 and $175 \mathrm{~mm}$ shell length) and allows fishing 


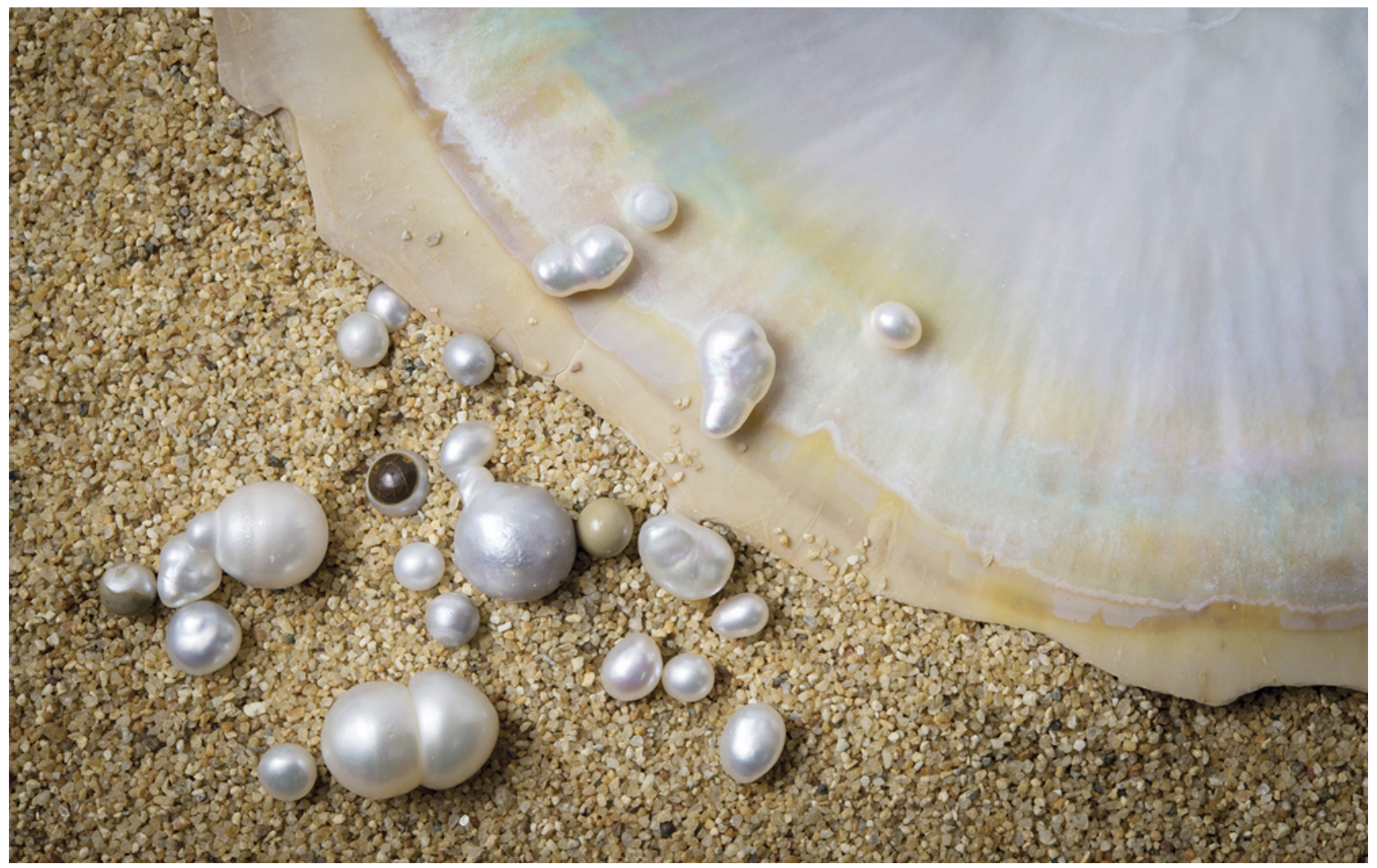

Figure 1. A selection of P. maxima cultured pearls (pictured with a P. maxima shell) randomly drawn from a total of 86 pearl samples examined. These consist of NBC pearls as well as BC samples with additional features attached to the surface ("Tokki pearls"). The largest center pearl measures $22.05 \times 14.07 \times 13.24 \mathrm{~mm}$. Photo by Nuttapol Kitdee.

within specific commercial pearl oyster fishery zones (Western Australia Department of Fisheries, 2016). Hatchery-bred shells are also used to supplement the wild stock (Gervis and Sims, 1992; Southgate and Lucas, 2008). Although BC pearls are the primary production goal, some NBC pearls are also unintentionally produced as a secondary product.

The general technique for cultivating saltwater BC pearls was originally developed for the Japanese akoya pearl culturing industry before being accepted for other culturing operations globally (Otter et al., 2017). It begins with the insertion of a bead nucleus (referred to as a seeding or nucleation process), along with a small piece of mantle tissue (saibo in Japanese) that is cut from a donor mollusk in a grafting process and subsequently inserted into the gonad of a living host mollusk (Al-Alawi et al., 2020; Sturman et al., 2020). Shell bead nuclei are usually fashioned from American freshwater mussels of the Unionidae family such as washboard (Megalonaias nervosa), ebony (Fusconaia ebena), and three-ridge (Amblema plicata), which are the most widely used source material for saltwater BC pearl production (Hsu et al., 2016; Sturman et al., 2020). Other materials have been used on an experimental basis in place of traditional shell beads, including plastic, resin, gemstones, dolomite, bironite, organic gelatinous polymer (superabsorbent polymer, or SAP), low-quality natural pearls, freshwater NBC pearls, and shell beads

\section{In Brief}

- Bead cultured (BC) pearls are primary products of pearl cultivation, and some non-bead cultured (NBC) pearls occur as a byproduct. NBC pearls are composed mainly of solid nacre, similar to natural pearls.

- $74 \mathrm{NBC}$ and $12 \mathrm{BC}$ pearls with intriguing additional surface features were collected directly from the gonads of operated Pinctada maxima mollusks, and their internal structures were analyzed using RTX and $\mu-C T$.

- Organic-rich concentric, void, and linear structural types were observed in the NBC samples and presented as associated additional features in the $\mathrm{BC}$ samples.

- Most NBC samples contained characteristic internal features that differentiated them from their natural counterparts. Nevertheless, some NBC samples showed particular structural forms comparable to the $P$. maxima natural pearls previously studied. 
produced from Tridacna shell (Snow, 1999; Hänni et al., 2010; Cartier and Krzemnicki, 2013; Cartier et al., 2013; Scarratt et al., 2017; Kessrapong and Lawanwong, 2020). However, none have matched the success of traditional freshwater mussel shell nuclei or been widely adopted for commercial use.

The grafted mantle tissue ideally consists of the outer ectoderm layer containing epithelium cells that are responsible for shell and pearl formation via the production of calcium carbonate $\left(\mathrm{CaCO}_{3}\right)$ polymorph aragonite in a brick-type arrangement, as well as organic matrix that is composed of proteins and polysaccharides (Crichton, 2019). Together these are referred to as nacre or mother-of-pearl (MOP). The epithelium cells within the gonad exist as a result of the grafted mantle tissue and are involved in the biomineralization process, while the host's gonad is the reproductive organ and cannot procreate $\mathrm{CaCO}_{3}$ (Hänni, 2012). After insertion, the epithelium cells multiply by cell division and link together to form a pearl sac that surrounds the bead nucleus and subsequently deposits nacre to form a pearl. Since this pearl sac is a result of the cultivation process, it is sometimes referred to as a "cultured pearl sac" in this study to differentiate it from a pearl sac that is naturally formed without any human intervention. The location from which mantle cells were extracted determines the type of calcium carbonate polymorph that results (Marie et al., 2012). Genetics, as well as the suitability of the mantle tissue selected, greatly impact the properties and quality of the resulting pearl (Otter et al., 2017). Therefore, the mantle tissue is usually selected from donor mollusks that have produced superior quality MOP exhibiting high luster and desirable color. Additionally, it is important to ensure that the transplanted mantle tissue maintains good contact with the bead nucleus and that the bead's resulting encapsulation by the pearl sac is as complete as possible before the nacre is secreted in order to form a high-quality BC pearl. The pearl sac will continue to produce nacreous layers around the bead nucleus as long as conditions are suitable for the host to do so or until the pearl is harvested. If the mantle tissue is not ideal, or the initial development of the pearl sac is not optimal, the pearl sac and additional features formed during nacre deposition may result in a baroque and/or lower-quality pearl. After harvesting the first BC pearls, farmers usually re-nucleate the mollusk, as the existing pearl sac is still productive and will accept a second bead (second operation). The P. maxima mollusk can be operated on up to three times, although in very rare cases four operations have occurred (Gervis and Sims, 1992). The number of operations will be determined by the mollusk's health and the quality of pearl produced.

In cases where the grafted mantle tissue separates from the bead, the mantle tissue continues to secrete nacre and the formation of a pearl sac is still possible. If the pearl sac does form, it is possible for an NBC pearl to develop (Southgate and Lucas, 2008; Hänni, 2012). It is also possible that individual epithelium cells will break away from the main mantle tissue during the first operation to form additional pearl sac(s). Such accidental pearl sacs function in the same way by secreting nacre and may form an unintentional NBC pearl, in parallel with the creation of the intended BC pearl forming in the primary pearl sac created by the original mantle tissue (Strack, 2006). This additional NBC pearl may form as a feature on the surface of a BC pearl, which may subsequently detach from the surface and appear to be a separate individual NBC pearl later. A BC pearl with an additional feature(s) attached to the surface is also known as a "Tokki pearl" (figure 1 and table 4; see also Krzemnicki et al., 2011). Tokki is a Japanese term referring to a surface protuberance. In yet another scenario, the bead nucleus is ejected from an already formed or partially formed pearl sac and an NBC pearl forms in its place (figure 2).

NBC pearls are mainly composed of nacreous layers similar to their natural counterparts, and they are often referred to as "keshi" in the market. However, this Japanese term (meaning "poppy seed") was originally used for natural saltwater seed pearls measuring 1-3 $\mathrm{mm}$ (Sturman and Al-Attawi, 2006), before being applied to byproducts found in the mantle area of Japanese akoya cultured pearls (Landman et al., 2001; Hänni, 2006). The World Jewellery Confederation (CIBJO) states that the use of "keshi" alone is misleading and inappropriate, and instead recommends using the term with a qualification such as "keshi cultured pearl" (CIBJO, 2020). The term "keshi" is not used on GIA pearl reports.

Three internal structural types-organic-rich concentric, void, and linear-have been reported in the majority of NBC pearls previously studied (Hänni, 2006; Wehrmeister et al., 2008; Sturman, 2009; Krzemnicki et al., 2010, 2011; Sturman et al., 2016, 2017; Nilpetploy et al., 2018a; Manustrong, 2018; Manustrong et al., 2019; Al-Alawi et al., 2020). Most NBC pearls show characteristic structural features belonging to these three groups that allow gemologists to differentiate them from natural pearls. However, some NBC pearls contain particular forms of these 


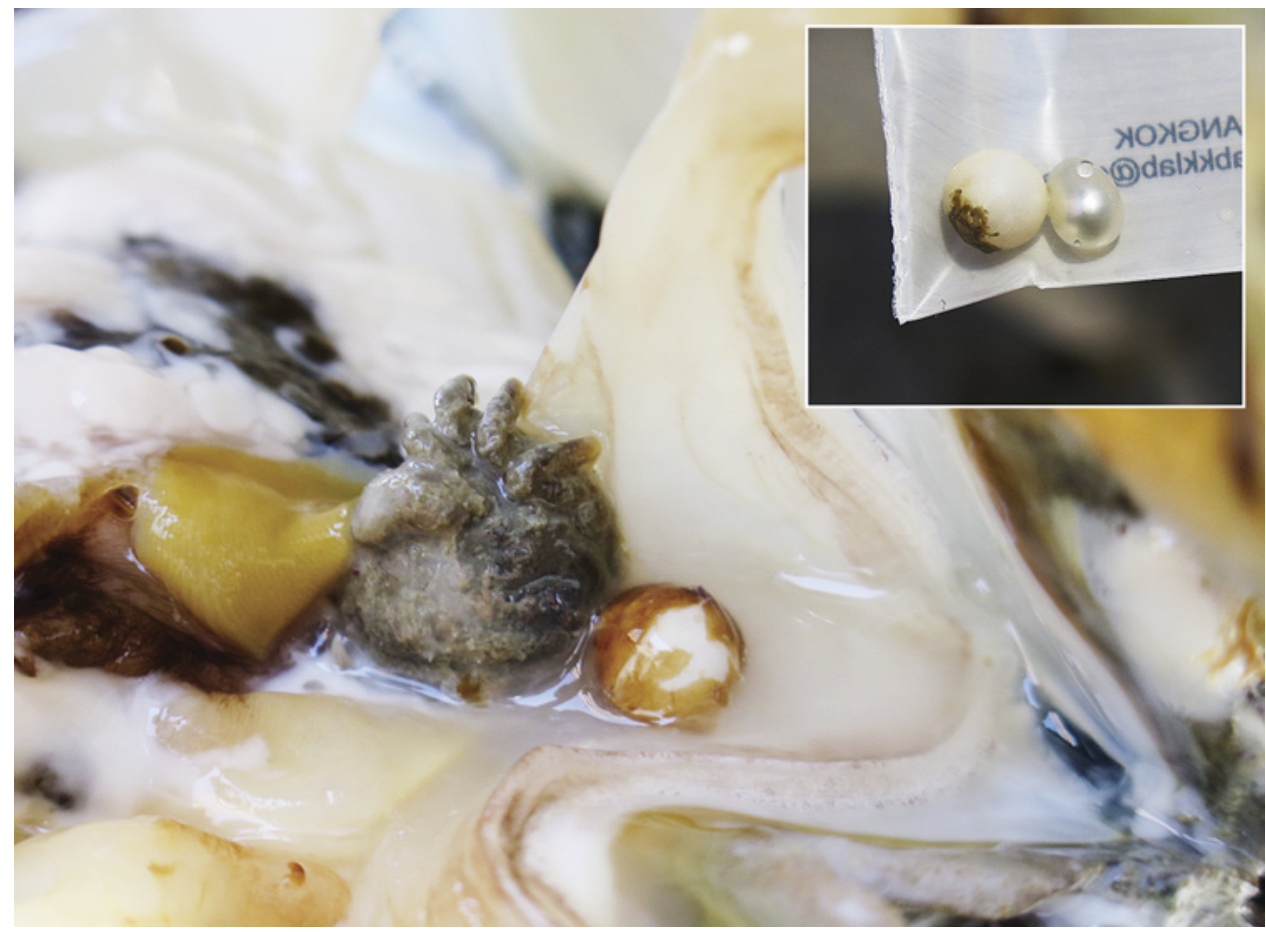

Figure 2. One example where the authors $(\mathrm{AH}$ and NN) found an ejected shell bead nucleus $(7.53 \times 6.94 \mathrm{~mm})$ inside a mollusk's gonad. When the shell was opened, a pea crab (Pinnotheres villosulus), which has a symbiotic relationship with P. maxima mollusks (Scarratt et al., 2012), was observed next to the ejected bead. A $6.92 \times 4.95 \mathrm{~mm} \mathrm{NBC}$ pearl (inset) was found together with the bead. Photos by Nanthaporn Nilpetploy.

structures that are comparable with those observed in natural pearls, or they contain complex overlapping structures that do not correspond with the structures typically observed in NBC pearls. Moreover, some natural pearls also possess structures that resemble those observed in NBC pearls. These can be challenging to correctly identify, especially when the pearls are submitted without any provenance (Scarratt et al., 2012; Sturman et al., 2019; Homkrajae et al., 2021). To better understand the characteristic internal features of $P$. maxima NBC pearls, as well as BC pearls with associated additional surface growths, the authors studied a selection of NBC and BC pearls grown in cultured pearl sacs and harvested directly from the gonads of operated mollusks. The various types of internal structure recorded in these samples are presented here, the second in a series of three articles that investigate the internal structures of P. maxima pearls produced by different growth mechanisms. The natural pearls retrieved directly from unoperated wild mollusks were covered in Homkrajae et al. (2021), and the final article will address pearls that form in the mantle area or adductor muscle, or are found attached to the shell of operated wild and hatchery mollusks.

Figure 3. A map showing the location of the Paspaley Pearling Company farm near Middle Osborn Island in Western Australia, where GIA collected cultured pearls from operated P. maxima mollusks. Image from Google Maps.

\section{MATERIALS AND METHODS}

In October 2014, two members of GIA's pearl team (authors $\mathrm{AH}$ and $\mathrm{NN}$ ) visited a farm owned and operated by the Paspaley Pearling Company located near Middle Osborn Island, off the coast of the Kimberley region in Western Australia, approximately $560 \mathrm{~km}$ southwest of Darwin (figure 3). The purpose of the trip was to collect known samples of South Sea cultured pearls (again, see figure 1), particularly NBC pearls, directly from cultured pearl sacs that had developed from pieces of mantle tissue inserted into the gonads of host mollusks. Throughout the seven-

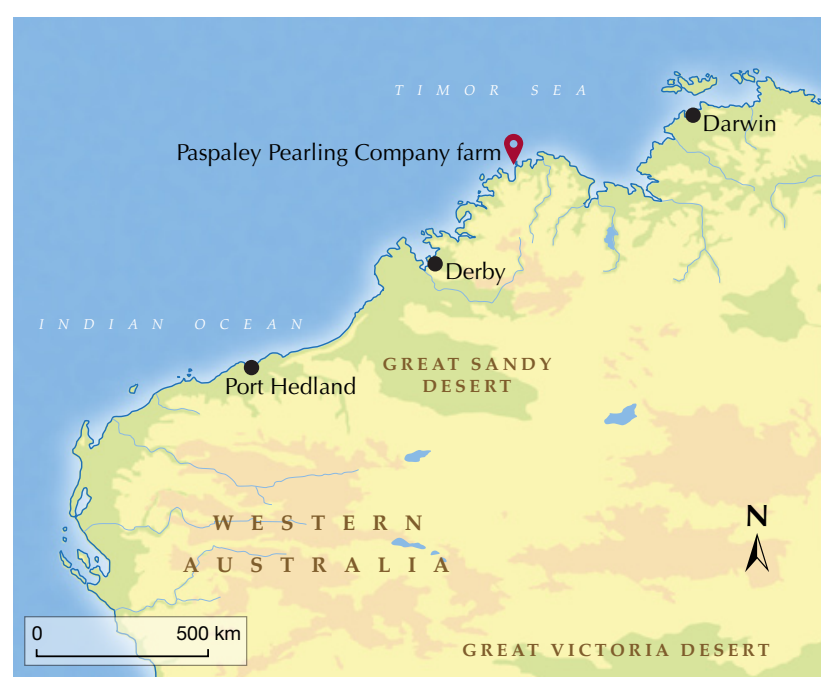


TABLE 1. Examples of NBC pearls from operated mollusks with organic-rich concentric structures (type 1).

\begin{tabular}{|c|c|c|c|c|}
\hline Sample details & $\begin{array}{l}\text { Position where found } \\
\text { in the mollusk }\end{array}$ & Macro image & RTX image & $\mu$-CT image \\
\hline \multicolumn{5}{|c|}{ Dark gray core } \\
\hline $\begin{array}{c}1-1 \\
\text { (3rd operation wild shell) } \\
0.35 \mathrm{ct} \\
3.95 \times 3.82 \times 3.08 \mathrm{~mm}\end{array}$ & & & & \\
\hline \multicolumn{5}{|c|}{ Light gray core } \\
\hline \multicolumn{5}{|l|}{$\begin{array}{c}1-2 \\
\text { (3rd operation wild shell) } \\
0.29 \mathrm{ct} \\
3.92 \times 3.78 \times 3.51 \mathrm{~mm}\end{array}$} \\
\hline \multicolumn{5}{|l|}{$\begin{array}{c}1-3 \\
\text { (3rd operation wild shell) } \\
0.66 \mathrm{ct} \\
4.80 \times 4.77 \mathrm{~mm}\end{array}$} \\
\hline \multicolumn{5}{|l|}{$\begin{array}{c}1-4 \\
\text { (3rd operation wild shell) } \\
0.30 \mathrm{ct} \\
4.10 \times 3.75 \mathrm{~mm}\end{array}$} \\
\hline \multicolumn{5}{|l|}{$\begin{array}{c}1-5 \\
\text { (3rd operation wild shell) } \\
0.33 \mathrm{ct} \\
4.04 \times 3.35 \mathrm{~mm}\end{array}$} \\
\hline \multicolumn{5}{|l|}{$\begin{array}{c}1-6 \\
\text { (3rd operation wild shell) } \\
1.05 \mathrm{ct} \\
6.04 \times 5.63 \mathrm{~mm}\end{array}$} \\
\hline \multicolumn{5}{|l|}{$\begin{array}{c}1-7 \\
\text { (2nd operation hatchery shell) } \\
2.08 \mathrm{ct} \\
7.97 \times 6.39 \mathrm{~mm}\end{array}$} \\
\hline $\begin{array}{c}1-8 \\
\text { (3rd operation wild shell) } \\
1.80 \mathrm{ct} \\
6.57 \times 6.50 \times 5.95 \mathrm{~mm}\end{array}$ & & & & \\
\hline
\end{tabular}

The position of the pearl in the mollusk is indicated by a red arrow.

day visit, nearly 925 mollusks from approximately 10,000 operated shells available were inspected, and a total of 86 cultured pearls (74 NBC and $12 \mathrm{BC}$ ) were selected for this study. Only the BC pearls with in- triguing surface protrusions were selected from the numerous BC pearls recovered.

GIA created pearl sample classification codes to differentiate the degrees of origin dependability, as 
TABLE 1. (continued).

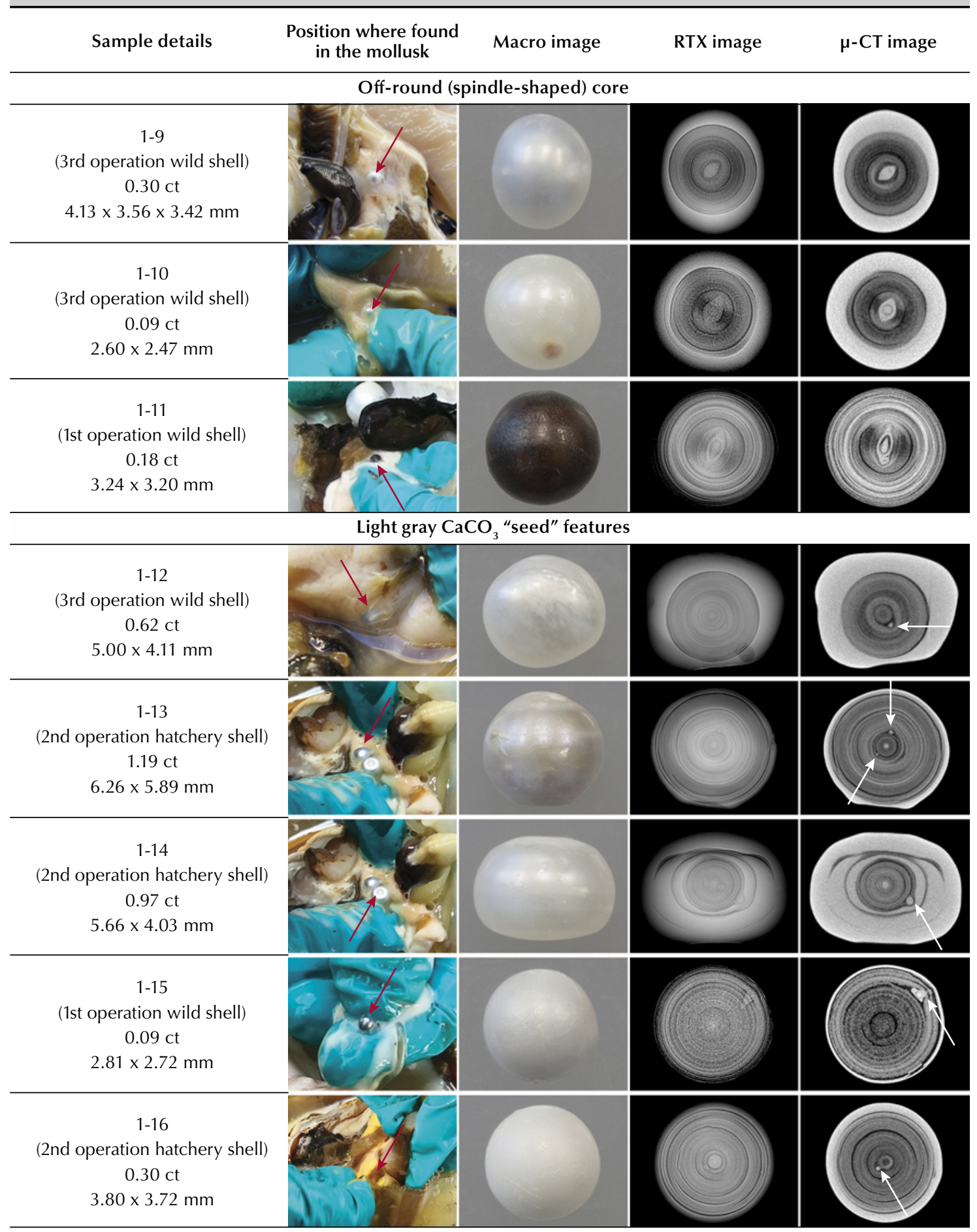

The position of the pearl in the mollusk is indicated by a red arrow. The white arrows indicate the light gray $\mathrm{CaCO}_{3}$ "seed" features (more radiopaque) observed.

previously described by Homkrajae et al. (2021; see table 1 of that article). Since 86 pearl samples in this study were harvested in situ from the gonads of freshly opened mollusks by two of the authors and their positions were documented by photos and videos, they are of known origin and may accordingly be classified as B1 samples (Homkrajae et al., 2021; see table 1). 


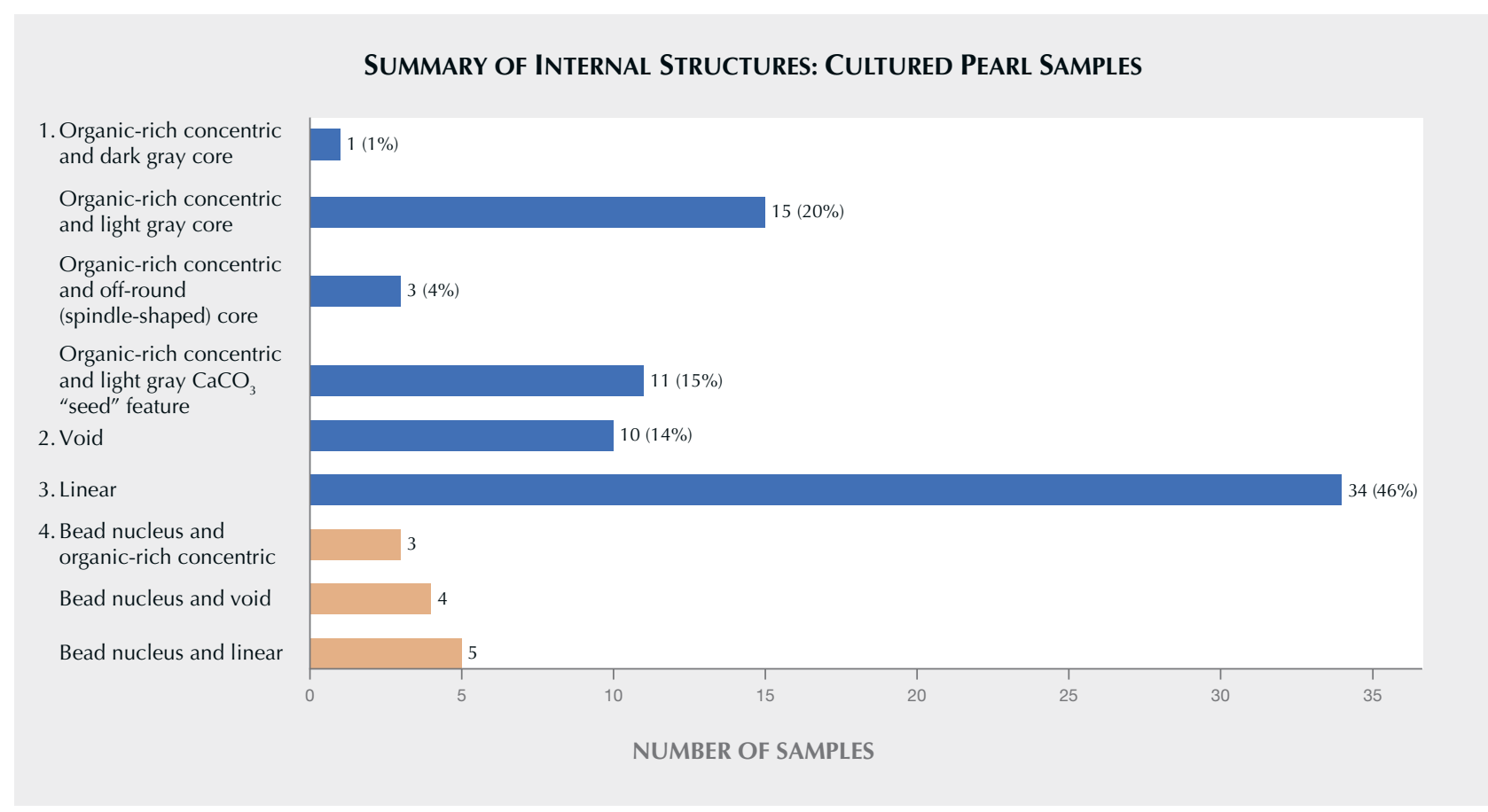

Figure 4. Summary of the four main internal structural types, including any variations found in the 86 cultured pearl samples studied (types 1-3 are observed in NBC and type 4 only in BC). The percentage of each structure recorded in the 74 NBC pearl samples is also shown.

The majority of the host mollusks (90\%) were wild shells collected from the ocean floor, while the remainder $(10 \%)$ were hatchery produced. The age and operation history of the host mollusks varied. Some were older and had already been operated on three times, while others were younger and had only been operated on once. The measurements and weights of the $74 \mathrm{NBC}$ pearls ranged from $1.80 \times 1.61$ $\times 1.28 \mathrm{~mm}$ to $10.42 \times 10.30 \times 8.50 \mathrm{~mm}$, and from 0.02 to $6.28 \mathrm{ct}$. The $12 \mathrm{BC}$ pearls measured from $14.80 \times$ $13.06 \times 12.35 \mathrm{~mm}$ to $32.51 \times 15.62 \times 15.40 \mathrm{~mm}$ and weighed from 14.31 to $43.33 \mathrm{ct}$.

The samples were loaned to GIA, and their internal structures were recorded using real-time microradiography (RTX) and X-ray computed microtomography $(\mu-C T)$. The RTX analysis was performed using a Pacific X-ray Imaging GenX-90P X-ray system with 4micron microfocus, $90 \mathrm{kV}$ voltage, and $0.16 \mathrm{~mA}$ current X-ray source with an exposure time of 200400 milliseconds per frame, combined with a PerkinElmer 1512 flat-panel detector with an average maximum of 128 frames and 74.8 micropixel pitch with $1944 \times 1536$ pixel resolution on all the samples. The samples that showed intriguing or indistinct structures were selected for more detailed viewing with $\mu$-CT. The $\mu$-CT work was carried out with a ProCon CT-mini X-ray system with a 5-micron microfocus, $90 \mathrm{kV}$ voltage, and a $0.18 \mathrm{~mA}$ X-ray current source. Two detectors with a frame grabber card were used to capture the results: a Hamamatsu C7921CA29 flat-panel detector with 50 micropixel pitch and $1032 \times 1032$ pixel resolution, and a Varex 1207 flatpanel detector with 74.8 micropixel pitch and $1536 \times$ 864 pixel resolution. RTX and $\mu$-CT data were collected in GIA's Bangkok laboratory. Photomicrographs were obtained to show certain features in greater detail using a Nikon SMZ18 stereomicroscope with an SHR Plan Apo 1× objective lens and NIS-Elements imaging software. As with Homkrajae et al. (2021), the purpose of this work was only to investigate the samples' internal characteristics.

\section{OBSERVATIONS AND RESULTS}

The characteristic internal features observed in the 86 cultured pearl samples using RTX and $\mu$-CT analyses can be categorized into four broad growth structural types (figure 4). Types 1-3 correspond to NBC samples, and type 4 applies to BC samples only.

1. Organic-rich concentric

2. Void

3. Linear

4. Bead nucleus and associated additional features

Thirty NBC and eight BC pearls from the samples studied were selected as representative samples to 
show the variations in the internal structures of the four main structural types and to serve as a reference for future pearl identification. Information and results for each sample are shown in tables 1 to 4 . The sample number, weight, measurements, and the number of times the mollusk was operated on are listed in the first column. The second column contains images showing the position of the pearl in each shell when retrieved (indicated by a red arrow). Macro, RTX, and $\mu$-CT results, respectively, are shown in the third through fifth columns. Since RTX and $\mu-\mathrm{CT}$ are microradiography techniques, all the relevant images in this study are shown in a grayscale intensity scheme. Thus, the internal growth patterns/features display varying intensities of gray corresponding to the differing X-ray densities or radiopacity of the materials that make up the pearls. $\mathrm{CaCO}_{3}$ polymorphs such as aragonite (nacre or shell bead) are mineralized materials that are denser to X-rays (more radiopaque) than organic-rich material or voids (i.e., areas filled with gases and/or liquids) that are more radiolucent and allow more Xrays to pass through (Wehrmeister et al., 2008; Sturman, 2009; Otter et al., 2014). Therefore, aragonite typically appears light gray, while organic-rich material or voids have a darker gray to black intensity. [Note: In this article, the description of an internal structure as "dark gray" and "light gray" corresponds to its X-ray density, not its actual color.]

Type 1: Organic-Rich Concentric Structures. Various organic-rich concentric structures were observed in 30 of the NBC pearl samples. Sixteen were selected as representative of these structures (table 1). Organic-rich concentric structures were visible as dark gray concentric layered areas in the center and occupied a large portion of the pearl's volume in most samples. The concentric structures in samples 1-4, 1-13, and 1-15 occupied most of the pearls' interior, and only a thin light gray layer corresponding to nacre was present on the outermost surface.

Most of the RTX images of the samples contained a dark gray (more radiolucent) or light gray (more radiopaque) core at the center of the concentric structures, similar to some observations in natural $P$. maxima pearls (Homkrajae et al., 2021). However, the core in each of these samples differed in size and form from those observed in the natural pearls. Only sample 1-1 showed a dark gray core consistent with those often encountered in natural pearls. Yet it is worth noting that the large area covered by the concentric structure and the lack of obvious growth fea- tures in the nacre overlying the structure are observations consistent with NBC pearls examined previously. This combination of features could lead to a wide range of opinions from different gemologists. The rest of the samples showed a light gray core composed of denser X-ray material similar in radiopacity to the outer nacreous layer. The majority of the cores appeared rounded (samples 1-2 through 1-8 and 1-12 through 1-16), and only three samples displayed offround (spindle-shaped) forms (samples 1-9 through 111). The sizes of the light gray core varied from large, in sample 1-2, to a tiny spot in sample 1-8. These cores resemble ones observed in natural pearls, though the very large cores in samples 1-2 and 1-3 have not been observed in any natural pearls to our knowledge. In sample 1-6, a twin center consisting of organic-rich concentric features with two light gray cores, one larger than the other, is intriguing as a similar twin structure was reported in a 0.11 ct natural pearl from a Pinctada maculata mollusk (Nilpetploy et al., 2018b). Nevertheless, the concentric growth layers in the center of sample 1-6 are much larger and more evenly spaced, and the distinct round light gray cores in the center of each organicrich feature, one larger than the other, are also absent in the natural P. maculata pearl (figure 5). Moreover, the acicular features shown within the organic-rich area in the natural $P$. maculata pearl are not present in sample 1-6. These differing aspects may also result in a wide range of identification calls. In the authors' opinion, the structure corresponds more closely with NBC pearls, and thus GIA would consider this pearl to be NBC. This is confirmed by the sample's provenance. Although an oval core has been observed in a natural pearl (Homkrajae et al., 2021), the authors believe that the spindle-shaped cores in samples 1-9 through 1-11 have only been reported in NBC pearls.

Light gray $\mathrm{CaCO}_{3}$ "seed" features of various size, shape, and quantity were revealed in different positions within the concentric structures (samples 1-12 through 1-16, indicated by the white arrows in table 1). These "seed" features are generally rounded and contain no discernible structure within, aside from sample 1-15 where the "seed" feature is irregularly shaped and a growth ring is present inside. Such $\mathrm{CaCO}_{3}$ "seed" features have previously been reported in South Sea and P. margaritifera (Tahitian) NBC pearls (Krzemnicki et al., 2010, 2011; Nilpetploy et al., 2018a), and they do not exist in any natural $P$. maxima pearls previously examined (Homkrajae et al., 2021). The presence of such $\mathrm{CaCO}_{3}$ "seed" features in association with organic-rich concentric 

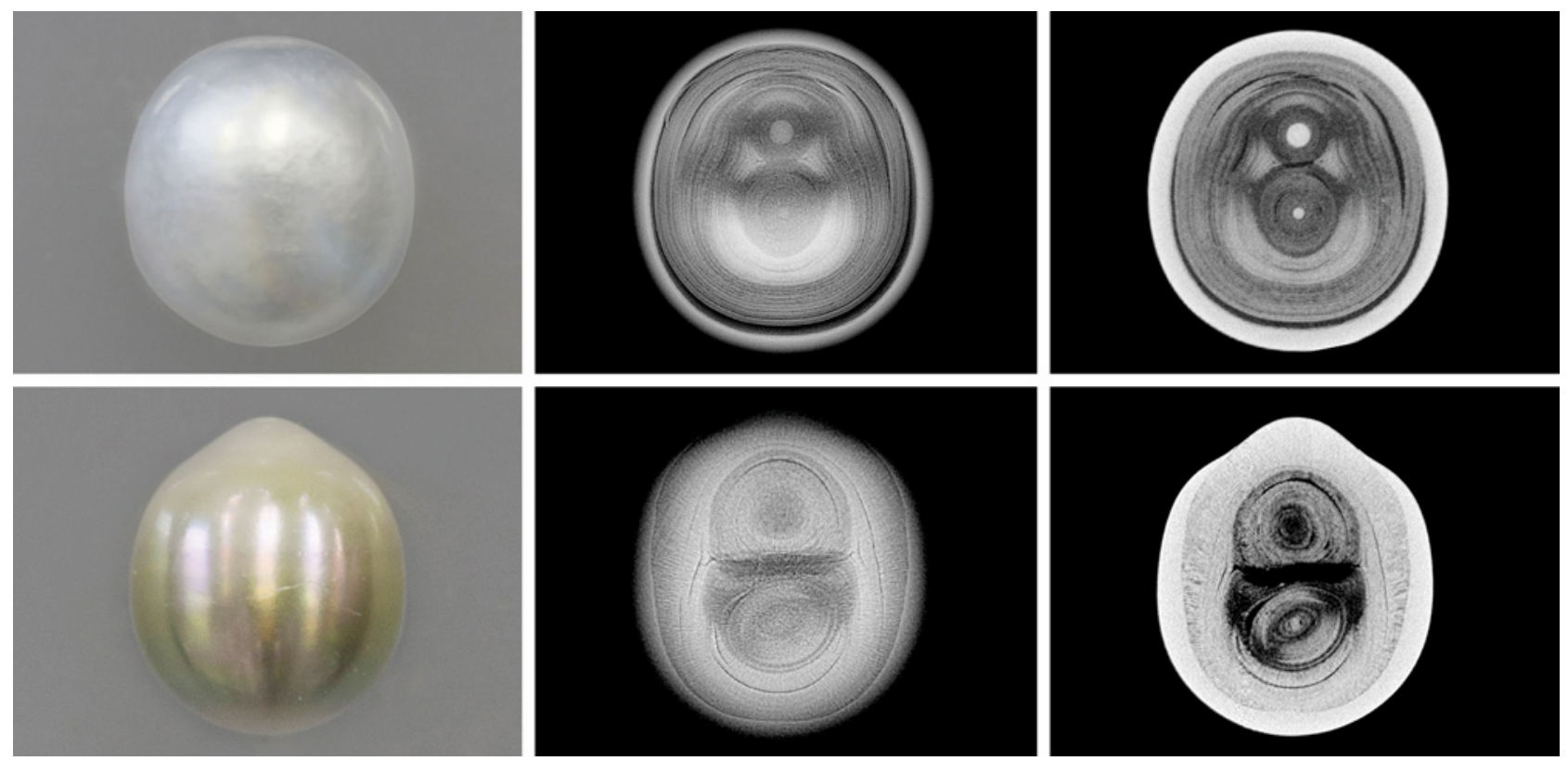

Figure 5. Macro images, RTX images, and $\mu$-CT slices of sample 1-6 (top row), and a 0.11 ct natural P. maculata pearl (bottom row) previously studied by Nilpetploy et al. (2018b; see sample I). Both pearls show similar twin organic-rich concentric features. However, sample 1-6 exhibits larger and more evenly spaced growth layers that incorporate two light gray cores at the center of each, one larger than the other, while the P. maculata natural pearl lacks these features and shows acicular formations within the organic-rich area. Photos by Sasithorn Engniwat.

structures is therefore a strong indicator of NBC formation. Additional details on similar $\mathrm{CaCO}_{3}$ "seed" features found in some non-nacreous P. maxima NBC pearls were covered by Manustrong et al. (2019; see table 4).

Some NBC pearls showed ambiguous structures or failed to reveal enough evidence to conclusively identify their origin. Samples 1-5 and 1-8 are good examples. Both showed relatively small areas of dark gray concentric layers, the light gray cores were small and rounded, no $\mathrm{CaCO}_{3}$ "seed" features appeared to exist, and a few growth structures were visible in the overlying nacre. In particular, the growth pattern of sample 1-8 (magnified in figure 6) closely resembles structures often observed in natural pearls from various Pinctada species (Krzemnicki et al., 2010; Scarratt et al., 2012; Nilpetploy et al., 2018b; Homkrajae et al., 2021) and is comparable to a $0.30 \mathrm{ct}$ known natural $P$. maxima

Figure 6. $\mu$-CT slices in three directions of sample 1-8 reveal a small area of organic-rich concentric structure, a tiny light gray core, and a few growth structures in the surrounding nacre. No CaCO "seed" features were observed within the organic structure. All these observations are consistent with natural pearls, not NBC pearls.
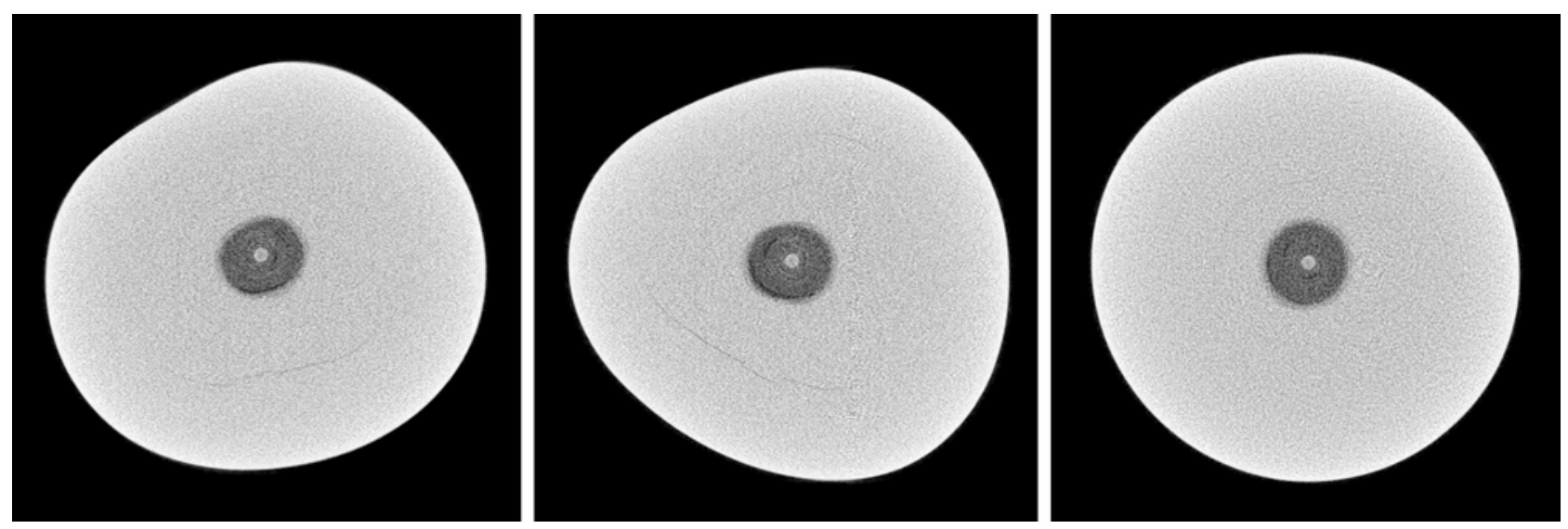

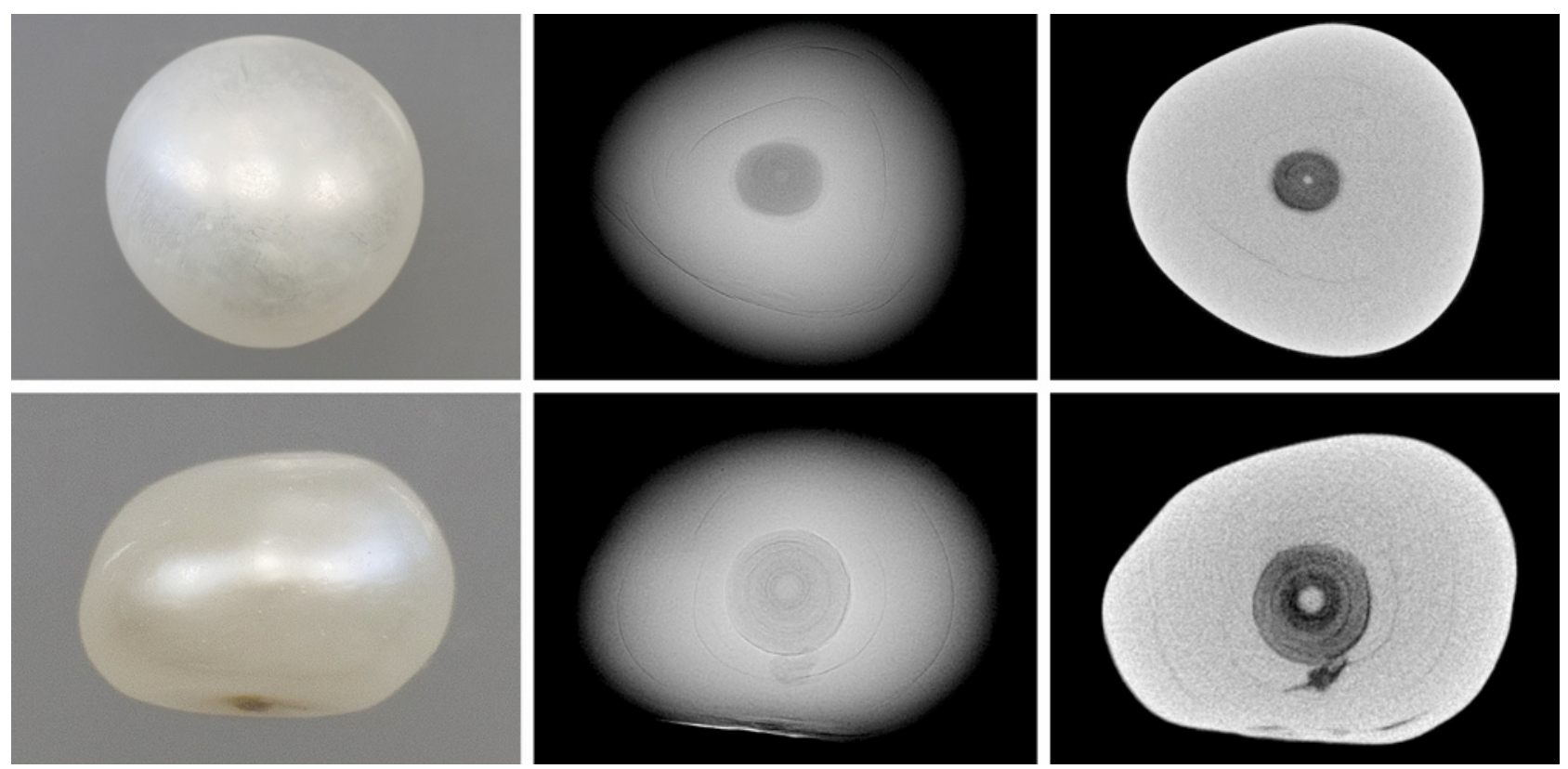

Figure 7. Macro images, RTX images, and $\mu$-CT slices of sample 1-8 (top row) and a 0.30 ct known natural P. maxima pearl (bottom row) previously studied by Homkrajae et al. (2021; see sample 2-9). Both pearls show similar internal structures. The light gray cores are relatively small, as are the dark gray concentric layers, and subtle growth patterns surround the central structures. Photos by Sasithorn Engniwat.

pearl sample (figure 7) previously studied by Homkrajae et al. (2021; see sample 2-9). It would be challenging to correctly identify such a pearl as NBC according to its known provenance, and it would almost certainly be classified as natural in standard laboratory testing conditions.

It is also interesting to note that some pearl samples were found together in the same mollusk and share similar internal characteristics. For example, samples 1-9, 1-10, and 1-12 were found together, and a BC pearl was also recovered from the same mollusk. They revealed large organic-rich concentric structures and lacked any growth structures in the surrounding nacreous areas. Samples 1-9 and 1-10 contained a spindle-shaped core, while sample 1-12's core is very small and rounded but also accompanied by a couple of "seed" features. Based on the combination of these internal characteristics, all three pearls would be classified as NBC. Samples 1-13 and 1-14 were found in the gonad next to one another, as shown by the images in the second column in table 1. While their organic-rich concentric structures are quite different in pattern and size, it was intriguing to note that both pearls contained the $\mathrm{CaCO}_{3}$ "seed" features within the concentric structure (magnified in figure 8). Another observation of note is that most of the samples in this group exhibited a nacreous sur- face, much like the vast majority of NBC $P$. maxima pearls, yet six samples displayed a non-nacreous surface. The external and internal characteristics of these non-nacreous NBC pearls were recorded in a detailed study by Manustrong et al. (2019), and two samples from that study are also included here (samples 1-4 and 1-11). Sample 1-7 showed both nacreous and non-nacreous surfaces. The nacreous surface exhibited a platy structure, while the non-nacreous part showed transparent features that were circular and bumpy, similar to those of the six non-nacreous samples included in this study.

Type 2: Void Features. Void and linear features are internal cavities or areas filled with gas and/or liquid phases, which are more transparent to X-rays (radiolucent) and appear on RTX and $\mu$-CT images as various tones of gray, usually dark, depending on size and volume. Because voids generally occupy a greater area than linear features (thin or slender voids) and therefore look different, they have been separated into different structural types in this article. Voids are often seen in saltwater NBC pearls, and gemologists use them to separate NBC from natural pearls. While $P$. maxima mollusks produce the majority of NBC pearls seen in the market, other Pinctada species also produce them (Wehrmeister et al., 2008; 

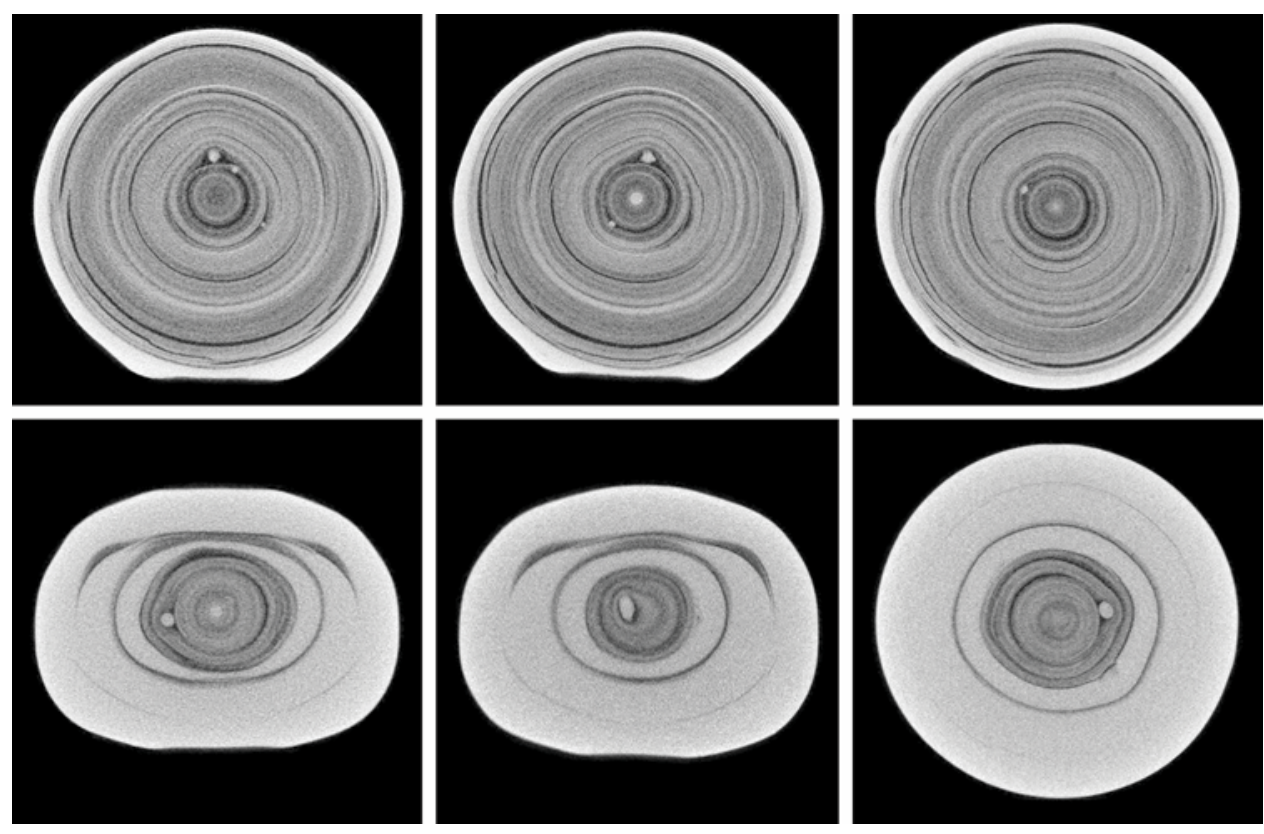

Figure 8. $\mu-C T$ slices in three directions of samples 1-13 (top row) and 1-14 (bottom row) reveal some light gray $\mathrm{CaCO}_{3}$ "seed" features within the concentric structures of both samples. They were found next to one another in the gonad of the same mollusk.
Sturman, 2009; Krzemnicki et al., 2010; Sturman et al., 2016, 2017; Nilpetploy et al., 2018a; Manustrong, 2018; Al-Alawi et al., 2020). Thus, it was unexpected that only 10 of the 74 NBC pearls in this study dis- played void features. Four were selected to show the various types of voids encountered (table 2). Most of the voids observed in this study were elongated (i.e., ellipse and ovoid cavities filled with gas and/or liquid

TABLE 2. Examples of NBC pearls from operated mollusks with void features (type 2).

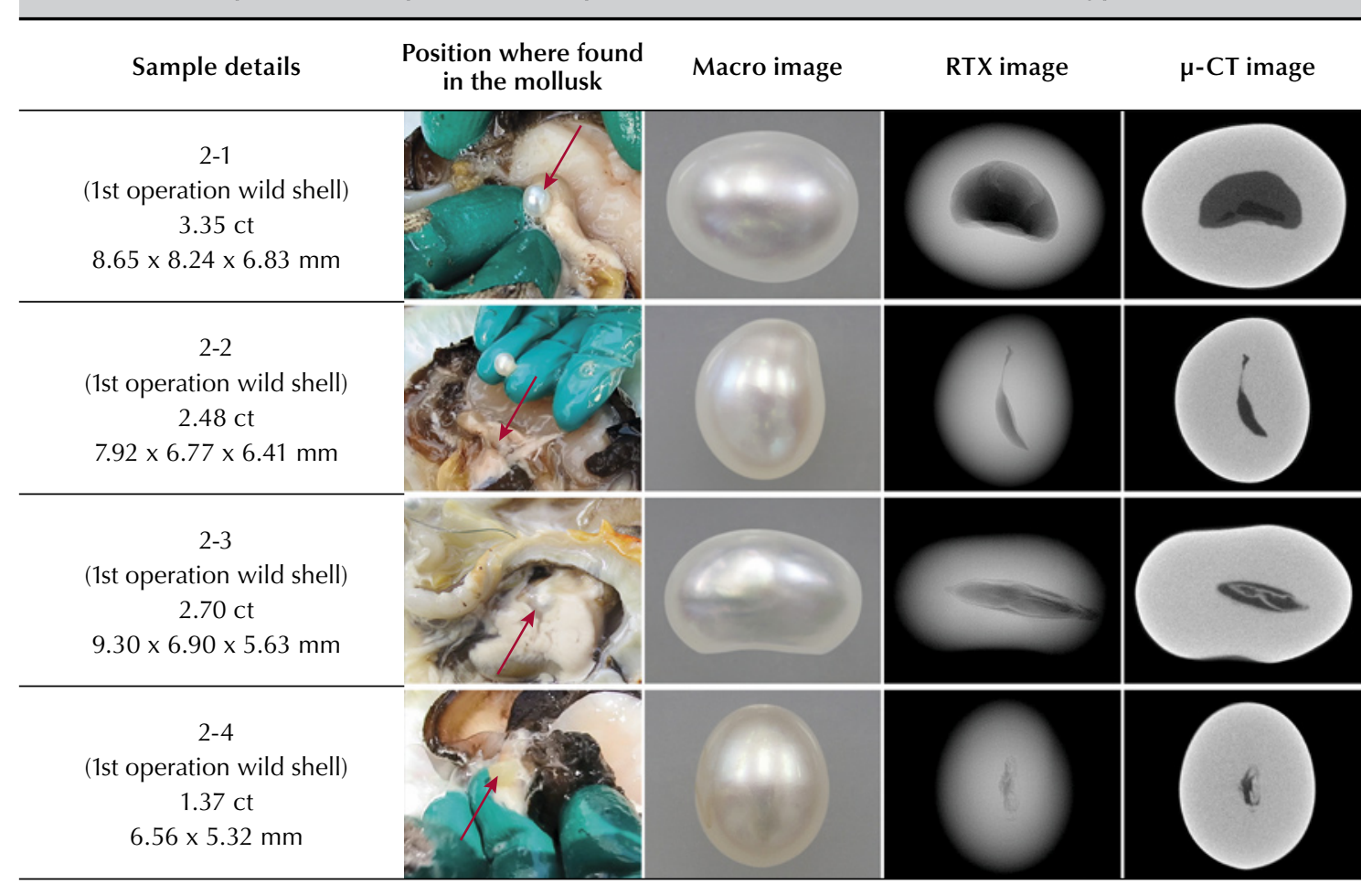

The position of the pearl in the mollusk is indicated by a red arrow. 

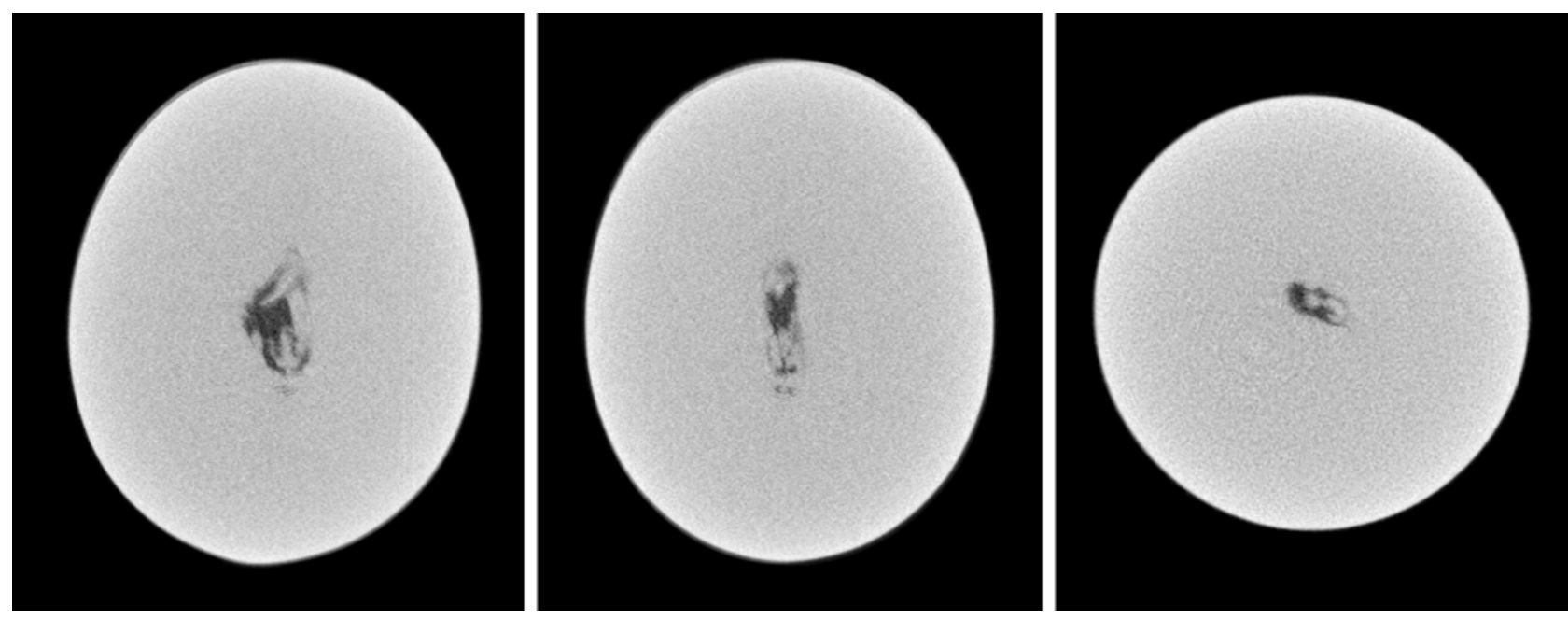

Figure 9. $\mu-C T$ slices in three directions of sample 2-4 reveal a combination of dark gray and light gray features inside the elongate void. This type of void is rarely observed in NBC pearls, and it has similarities to some previously observed in natural pearls.

phases) and oriented along the longest direction of the pearl. The light gray, representing the overlying nacre around the voids, was generally tight or only contained a few growth lines comparable with most NBC pearls in the type 1 group. Although only single voids were observed in samples from this study, double or multiple voids are sometimes observed in NBC pearls (Sturman et al., 2016).

Sample 2-1 revealed a large void that took up nearly half of the pearl's volume. However, the void is not entirely empty, as a dark gray material can be seen within the virtually black center. This material could be a semi-solid organic-rich phase that is found in many voids in pearls both natural (Homkrajae et al., 2021) and cultured (Otter et al., 2014, Nilpetploy et al., 2018a). However, the organic-rich feature lacks any fine growth structure, which is uncharacteristic of natural pearls. Based on the large void's absence of any clear growth structure in the organic-rich area, the pearl would be identified as NBC. The hollow slender void present in sample 22 is characteristic of voids found in many saltwater NBC pearls. Sample 2-3 showed a central cavity with an inner light gray feature with a radiopacity similar to that of the nacre. This type of void feature has been reported in some NBC pearls from $P$. margaritifera (Nilpetploy et al., 2018a) and Pinctada fucata (martensii) (Manustrong, 2018). It has also been observed in some saltwater NBC pearls submitted for examination in GIA's global laboratory locations. Sample 2-4 displayed a combination of dark gray and light gray features inside the elongated void that is sometimes observed in NBC pearls (magnified in figure 9). However, similar alternating dark and light gray patterns have been observed in some natural pearls (Homkrajae et al., 2021), and thus it is possible that some gemologists would identify this pearl as natural. Conversely, some gemologists could interpret the elongated shape and position of the void to be more typical of NBC pearls. This complex divergence reveals the challenges gemologists face in pearl identification, and an inconclusive opinion may well be the result.

Type 3: Linear Structures. Linear structures are the most common type encountered in NBC pearls produced by various mollusks originating from saltwater and freshwater environments (Scarratt et al., 2000; Hänni, 2006; Sturman, 2009; Krzemnicki et al., 2010; Sturman et al., 2016, 2017; Nilpetploy et al., 2018a; Manustrong, 2018; Al-Alawi et al., 2020; Kessrapong and Lawanwong, 2020). Not surprisingly, almost half of the NBC samples showed linear features, and 10 samples with various forms of these are presented in table 3. Samples 3-1 through 3-4 showed classic linear structures typically observed in NBC pearls. The extended linear feature displayed is the dominant structure seen running the length of each pearl. Even though samples 3-1 and 3-2 look different externally, they were harvested from the gonad of the same mollusk and share similar linear structures.

The linear structures visible in samples 3-5 through 3-10 are more complex, and some are seldom 
TABLE 3. Examples of NBC pearls from operated mollusks with linear structures (type 3).

\begin{tabular}{|c|c|c|c|c|}
\hline Sample details & $\begin{array}{l}\text { Position where found } \\
\text { in the mollusk }\end{array}$ & Macro image & RTX image & $\mu$-CT image \\
\hline $\begin{array}{c}3-1 \\
\text { (3rd operation wild shell) } \\
5.37 \mathrm{ct} \\
14.18 \times 9.16 \times 6.29 \mathrm{~mm}\end{array}$ & & & & \\
\hline $\begin{array}{c}3-2 \\
\text { (3rd operation wild shell) } \\
0.39 \mathrm{ct} \\
4.36 \times 3.40 \mathrm{~mm}\end{array}$ & & & & \\
\hline $\begin{array}{c}3-3 \\
\text { (3rd operation wild shell) } \\
3.06 \mathrm{ct} \\
11.65 \times 7.00 \times 5.45 \mathrm{~mm}\end{array}$ & & & & \\
\hline $\begin{array}{c}3-4 \\
\text { (1st operation wild shell) } \\
1.21 \mathrm{ct} \\
6.92 \times 4.95 \mathrm{~mm}\end{array}$ & & & & \\
\hline $\begin{array}{c}3-5 \\
\text { (3rd operation wild shell) } \\
0.28 \mathrm{ct} \\
3.96 \times 3.49 \times 2.76 \mathrm{~mm}\end{array}$ & & & & \\
\hline $\begin{array}{c}3-6 \\
\text { (2nd operation hatchery she } \\
0.535 \mathrm{ct} \\
6.31 \times 3.89 \times 2.90 \mathrm{~mm}\end{array}$ & & & & \\
\hline $\begin{array}{c}3-7 \\
\text { (3rd operation wild shell) } \\
0.22 \mathrm{ct} \\
3.37 \times 3.11 \mathrm{~mm}\end{array}$ & & & & \\
\hline $\begin{array}{c}3-8 \\
\text { (3rd operation wild shell) } \\
0.70 \mathrm{ct} \\
5.51 \times 4.78 \times 3.60 \mathrm{~mm}\end{array}$ & & & & \\
\hline $\begin{array}{c}3-9 \\
\text { (3rd operation wild shell) } \\
3.96 \mathrm{ct} \\
15.30 \times 6.28 \times 5.65 \mathrm{~mm}\end{array}$ & & & & \\
\hline $\begin{array}{c}3-10 \\
\text { (2nd operation hatchery she } \\
2.10 \mathrm{ct} \\
9.88 \times 7.20 \times 5.14 \mathrm{~mm}\end{array}$ & & & & \\
\hline
\end{tabular}

The position of the pearl in the mollusk is indicated by a red arrow. The white arrows indicate the small linear or void structures at the core of each defined demarcation. 

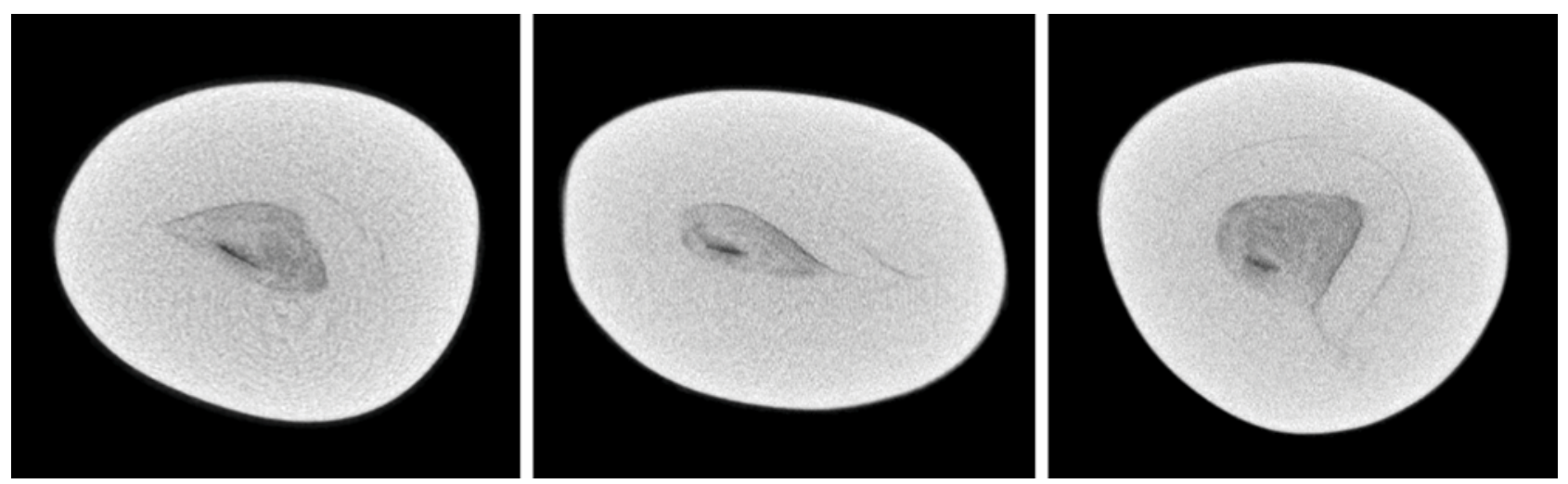

Figure 10. $\mathrm{\mu -CT}$ slices in three directions of sample 3-5 reveal a dark gray line inside an area of organic-rich growth. Although the linear feature appears characteristic of NBC pearls, the organic-rich growth structure is more typical of natural pearls.

encountered in NBC pearls. Therefore, the identification of some NBC pearls is not straightforward. Sample 3-5 revealed a pear-shaped dark gray, organic-rich structure with an unclear associated darker feature in the RTX image that appears more likely to be a natural pearl structure. However, the dark feature shows up more clearly (magnified in figure 10) when analyzed by a high-resolution $\mu$-CT unit, and it appears to be more linear and thus possibly more characteristic of some NBC pearls. Yet this feature does not correspond with the majority of linear associated structures observed in NBC and natural pearls, and therefore an inconclusive opinion may result. However, some gemologists may consider the linear feature sufficient evidence to identify this pearl as NBC, which would be consistent with its recorded provenance.

Distinct layered growth structures enclosing a linear feature, as shown in samples 3-6 and 3-7, are not typically encountered in NBC pearls. This is because NBC pearls generally lack any growth layers/features in the surrounding nacre, as has already been noted, although the linear features in the center commonly correspond with those observed in other NBC pearls. Moreover, similar growth layers of alternating light and dark gray features related to the difference in organic content have been observed in some natural pearls (Homkrajae et al., 2021; see figure 15). Samples 3-8 through 3-10 showed combination structures consisting of multiple cores or segments, as well as linear features. Samples 3-8 and 3-9 revealed a long linear structure in the main body with shorter linear or void features in the center of each segment (table 3, indicated by the white arrows). On the other hand, the main body of sample 3-10 showed only growth rings and no evidence of a linear feature (magnified in figure 11). Only when the other segments were inspected were linear or void features revealed (table 3 , indicated by a white arrow). The structures presented in samples 3-8 and 3-9 are more characteristic of NBC pearls (Nilpetploy et al., 2018a). While the linear features visible in the small segments point to an NBC origin, the overall structure of sample $3-10$ is doubtful and this pearl may be considered inconclusive.

Figure 11. $\mathrm{u}$-CT slices in three directions of the largest segment of sample 3-10 only revealed growth rings. However, linear features and voids are present in other parts. The overall internal structure is doubtful and points to an NBC origin.
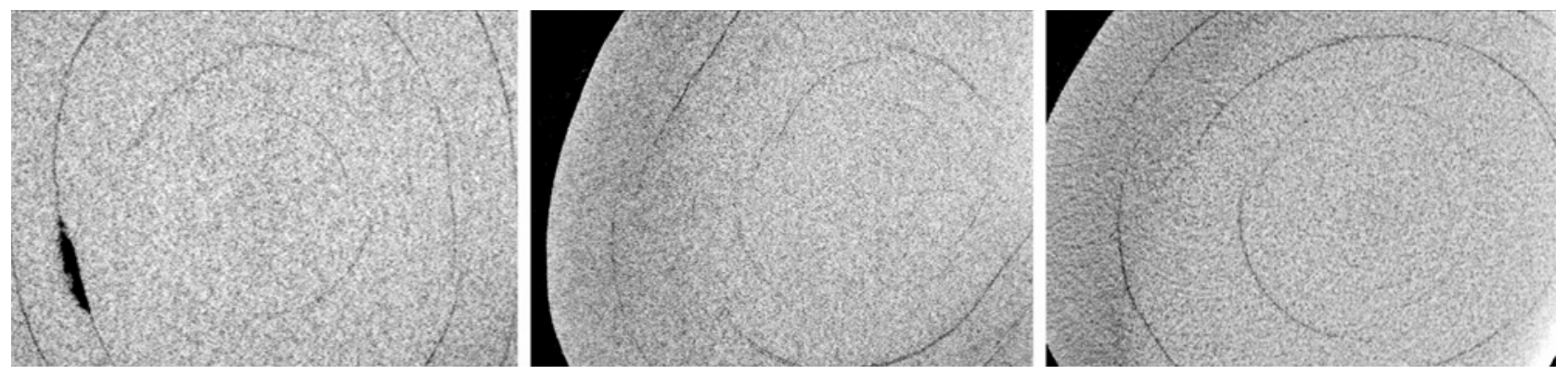
TABLE 4. Examples of BC pearls from operated mollusks with a bead nucleus and associated additional features ("Tokki") (type 4 only in BC).

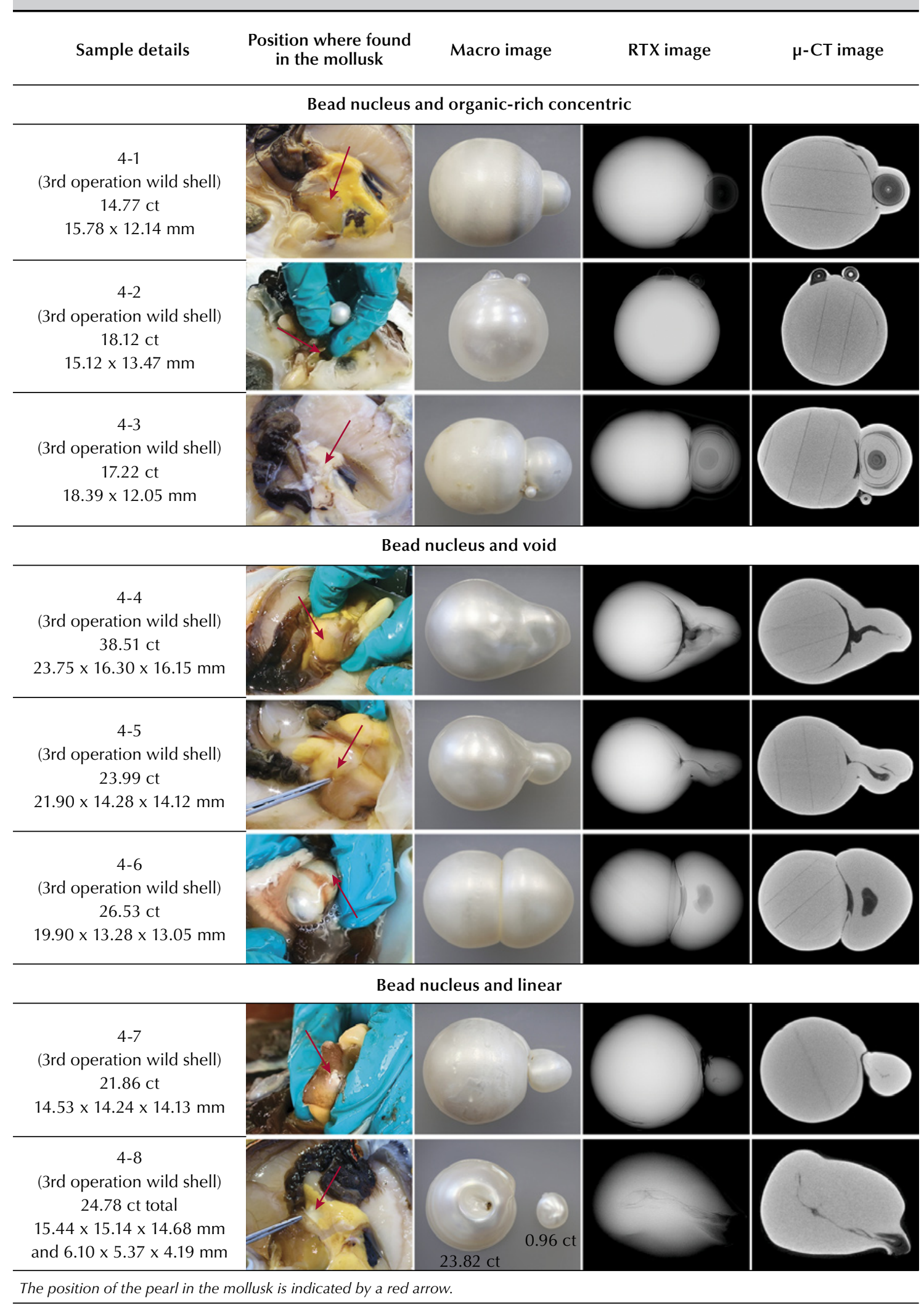



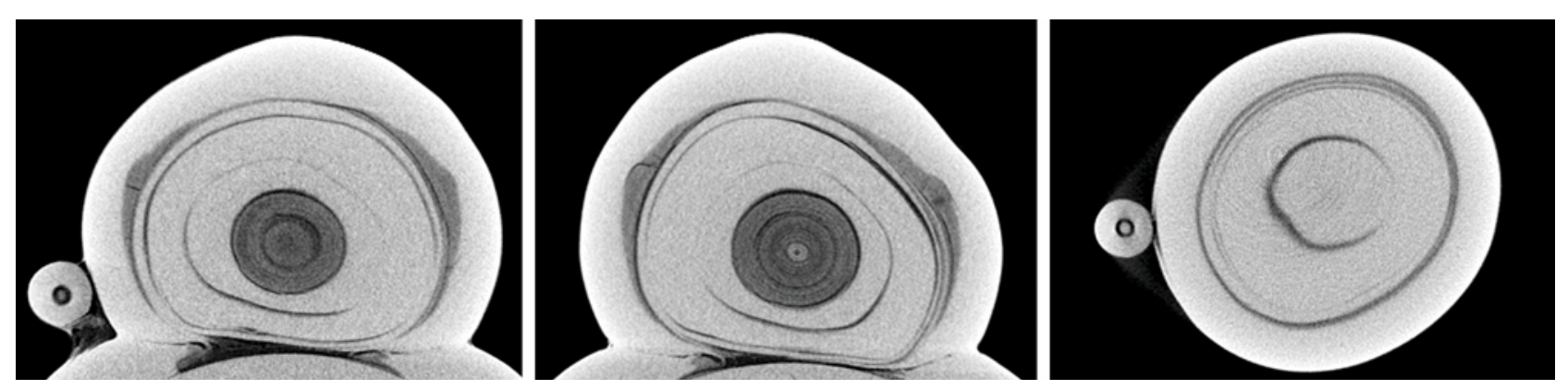

Figure 12. u-CT slices in three directions of sample 4-3's feature revealed an organic-rich concentric structure that formed next to the bead nucleus. The small dark gray concentric area, tiny light gray core, and growth layers surrounding the dark gray area are similar to some observed in natural rather than NBC pearls.

Type 4: Bead Nucleus and Associated Additional Features. Twelve BC pearls with potentially intriguing additional features were selected from the many BC pearls recovered during the harvest. These additional features displayed organic-rich concentric, void, and linear features similar to the structures typically encountered in NBC samples; eight representative samples are shown in table 4 . The additional features directly affected the pearls' external appearance, often resulting in baroque shapes. Although the pearls possessed additional features, their main body contained a bead nucleus and thus they would be classified as BC pearls. These extra features can form next to the bead nucleus (samples 4-1, 4-4, and 4-5) or independently from the bead nucleus and still be firmly attached to the outer nacreous layers (samples 4-2, 4-3, and 4-6). They may also form independently from the $\mathrm{BC}$ pearl and be loosely attached to the surface, where they are likely to separate later and become individual NBC pearls (samples 4-7 and 4-8).

As with all bead cultured pearls examined by RTX, the bead nuclei showed a distinct round dark gray feature at the interface between the beads themselves and the point of initial nacre contact. Some demarcation rings are more obvious than others, usually depending on the amount of organic matter deposited by the mollusk after the nucleation procedure has ended and the initial recovery period takes place. Straight parallel lines related to the banded structure of the shell bead nucleus, or boundaries delineating multiple sections of shell used to create laminated beads (Manustrong and Lawanwong, 2020), are also sometimes observed inside the main demarcation boundary.

Organic-rich concentric structures visible on samples 4-1 through 4-3 manifest themselves as rounded protrusions on the pearl surface. This type of additional feature is commonly associated with $\mathrm{BC}$ pearls and has been reported in cultured pearls produced by Pinctada species mollusks (Krzemnicki et al., 2010, 2011; Al-Alawi et al., 2020). They may form as single, double, or multiple growths. RTX and $\mu-C T$ analyses revealed the dark gray organic-rich concentric structures constituting the majority of the features in samples 4-1 and 4-2. This is in keeping with the structures of most type $1 \mathrm{NBC}$ samples, and to a lesser degree with the organic-rich concentric structures found in the natural P. maxima pearls previously reported by Homkrajae et al. (2021); see type 2 in that article. In contrast, sample 4-3 showed an organic-rich concentric structure similar to that of some natural pearls. The structure consisted of a small dark gray concentric area, a tiny light gray core, and growth structure surrounding the dark gray area (magnified in figure 12). If this additional feature were to become detached, resulting in a separate pearl, it would be challenging to identify the origin correctly. The additional features in samples 4-4 through 4-8 exhibited voids or linear structures. Those in samples 4-4 and 4-5 are associated directly with the bead nuclei, while the feature in sample 4-6 forms in the center and is not in contact with the bead nucleus. Sawing would be required to separate the additional features from the main bead cultured pearl in samples 4-1 through 4-6, as they are firmly attached to each other. Samples 4-7 and 4-8 showed a fine linear structure at the center of their additional features. When harvested, they were loosely attached to the main BC pearls. Later, the thin nacreous and organic-rich layer that bonded the features to the main $\mathrm{BC}$ pearls dried out, resulting in the separation of individual NBC pearls. Remnants of the organic-rich bond that held the two sections of sample 4-7 prior to separation, as well as the area where both segments were attached, are shown in figure 13. 

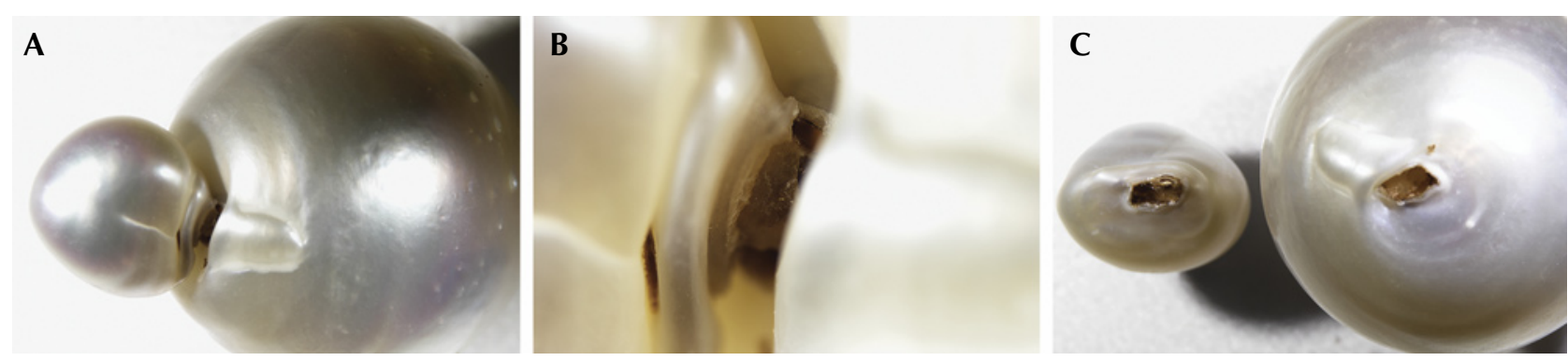

Figure 13. Photomicrographs of sample 4-7, showing the area where both segments were loosely attached at the time of harvest (A and B; field of view $19.20 \mathrm{~mm}$ and $4.80 \mathrm{~mm}$, respectively). Over time, the bonding dried out and the two parts separated into individual pearls: $N B C$ on the left and $B C$ on the right $(C$; field of view 19.20 mm). Photos by Nanthaporn Nilpetploy.

\section{DISCUSSION}

Various forms of internal structure were observed in the 74 NBC P. maxima pearls studied, although they can simply be classified into three broad types: organic-rich concentric structures $(40 \%)$, void features $(14 \%)$, and linear structures $(46 \%)$. These three structural types were also noted as associated additional features in $12 \mathrm{BC}$ pearls investigated. More importantly, certain forms of these structures were reported in some natural pearls, which highlights the challenges in separating some NBC from natural pearls, especially when tested in laboratory conditions and their provenance is unknown (Sturman et al., 2019).

Organic-rich concentric structures have been reported in cultured pearls produced by Pinctada species mollusks (Krzemnicki et al., 2010, 2011; Sturman et al., 2017; Nilpetploy et al., 2018a; Manustrong et al., 2019; Al-Alawi et al., 2020), and some natural pearls formed by various mollusk species (Krzemnicki et al., 2010; Scarratt et al., 2012; Sturman et al., 2014; Karampelas et al., 2017; Nilpetploy et al., 2018b; Homkrajae et al., 2021). Some differences noted by the authors could be useful indicators in distinguishing NBC pearls from their natural counterparts. The organic-rich concentric areas in most NBC samples are generally large and cover over half of the pearl's interior, whereas the concentric layered areas in natural samples tend to occupy a relatively small portion of the interior. The concentric rings within the organic-rich areas are more distinct and uniformly arranged in NBC samples than in natural pearls, although in some NBC samples the rings seem to cross over and merge with others. This uniformity is not observed in natural samples. An uneven or "spotty" appearance was visible in the dark concentric layered areas of some NBC samples but not apparent in the natural pearls. Dark and light gray cores were observed within the dark concentric organic structures of both NBC and natural pearls, but only one NBC sample exhibited a dark core. In contrast, many of the natural pearls contained a dark gray core, which would seem to indicate a natural rather than NBC origin. The light gray cores usually appeared tight (radiopaque) and rounded in both kinds of pearls, yet the very large light gray cores were only observed in NBC pearls, while the majority of light gray cores seen in the natural pearls were small. The off-round (spindle-shaped) light gray cores and light gray $\mathrm{CaCO}_{3}$ "seed" features observed in different positions within the dark gray organic-rich concentric structures were found in NBC but not natural pearl samples. When two or more of these characteristic features are combined, they provide sufficient proof to classify a pearl as NBC. Additionally, the dark gray organic-rich concentric structures within most of the NBC samples appeared uniformly symmetrical in shape with near-round, oval, and button outlines, while those in the natural pearls were of various shapes and many appeared asymmetrical.

Voids and linear structures are known to be key identification features for NBC pearls produced by Pinctada species mollusks (Wehrmeister et al., 2008; Sturman, 2009; Krzemnicki et al., 2010; Sturman et al., 2016, 2017; Nilpetploy et al., 2018a; Manustrong, 2018; Al-Alawi et al., 2020). However, a small percentage of natural saltwater pearls have also been shown to contain these two structural types (Scarratt, 2019; Homkrajae et al., 2021). Around $14 \%$ and $46 \%$ of all NBC pearl samples studied in this work displayed void and linear features, respectively. Both structural types, especially the linear structures encountered in NBC samples in this study and previous studies, share the common characteristic of being elongated and extending the length of the pearl. Usually, the linear features also extend over half of the pearl's length. Voids in natural pearls range in size and can be large, but in Homkrajae et al. (2021) the samples appeared to oc- 
cupy relatively small portions, approximately $30 \%$ or less of the pearl's volume, and revealed organic-rich growth features within the voids when examined by $\mu-C T$. These differences are helpful in distinguishing NBC from natural pearls. By comparison, linear structures are the most challenging to interpret in natural pearls. However, linear structures are typically observed in NBC pearls and less frequently in natural pearls, although the chances increase when extremely baroque pearls are considered. All the natural samples that were found to contain linear features tended to be baroque (Homkrajae et al., 2021), whereas linear features were observed in both baroque and symmetrically shaped NBC pearls such as the oval and drop shapes (samples 3-2 and 3-4). Therefore, any pearl with a distinct linear feature would most likely be identified as NBC.

What follows are the identification characteristics observed for the three main structural categories from the known natural and NBC P. maxima pearl samples (figure 14). The first category includes the structures that were only found in natural pearl samples. The structures that fall into this category are (1) tight or minimal growth that lack any clear internal growth features or only showed a few weak growth patterns; (2) an organic-rich concentric structure and patchy light and dark gray center resulting from differences in the organic content within these areas;
(3) a dense, solid light gray core not enclosed by any clear organic-rich concentric structure; and (4) a marine organism entombed by nacre deposition. Severely fractured central internal structures were found only in natural pearl samples (Homkrajae et al., 2021; see samples 6-5 and 6-6), yet they appear to be related to later stages of the pearls' formation and not their initial formation. Therefore, this type of structure may also be observed in NBC pearls and cannot be used as an indicator of a pearl's identity.

The second category involves the internal structures that are only found in NBC samples, including (1) an organic-rich concentric structure and off-round (spindle-shaped) core and (2) an organic-rich concentric structure and accompanying light gray $\mathrm{CaCO}_{3}$ "seed" feature.

The last category includes overlapping structures that have been observed in natural and NBC pearl samples. Therefore, they are less indicative of any specific type of pearl unless certain internal characteristics previously mentioned are considered. These structures include (1) an organic-rich concentric structure and dark gray core, (2) an organic-rich concentric structure and light gray core, (3) void features, and (4) linear structures.

Lastly, NBC pearls often form after the mollusk has rejected the bead nucleus and the empty pearl sac continues to produce an accidental pearl. This can

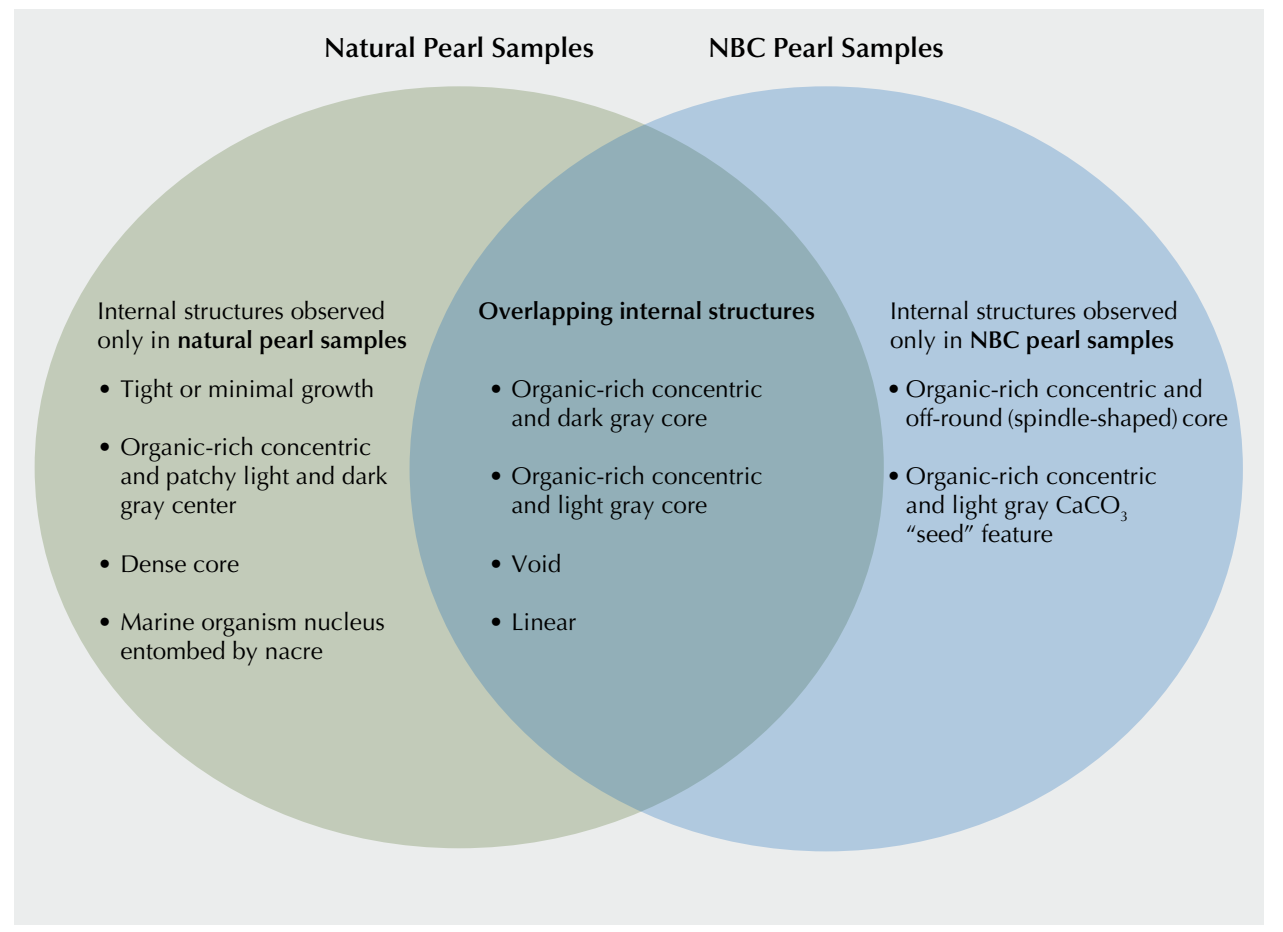

Figure 14. A diagram illustrating the three main categories of internal structures as radioimages. The two circles represent internal structures observed only in known natural P. maxima pearl samples in Homkrajae et al. (2021, left) and known NBC P. maxima pearl samples in this study (right). The area of overlap represents internal structures found in both natural and NBC pearl samples. 
occur during the first operation or in any subsequent operations the mollusk endures during its life. It is worth noting that many of the NBC pearl samples with distinct linear features formed in mollusks following their second or third operation, and they often exhibit a flattened baroque shape. This observation is in agreement with studies by Hänni (2006) and Krzemnicki et al. (2010). Additionally, organic-rich concentric structures were discovered in NBC pearls from all three operations, and $\mathrm{BC}$ pearl samples with the additional surface features were produced by mollusks following the third operation.

\section{CONCLUSIONS}

Organic-rich concentric structures, void features, and linear structures are the three main structural types found in the NBC pearl samples studied, and within the additional features found on the $\mathrm{BC}$ pearls examined. The majority of the NBC samples exhibited one of two typical internal characteristics-relatively large voids or distinct linear features-helping prove their cultured origin. Other structural features help identify pearls as NBC when observed in conjunction with each other or with the two main NBC structures. These include a large light gray core, an offround (spindle-shaped) core, and light gray $\mathrm{CaCO}_{3}$ "seed" features found within organic-rich concentric structures. However, as discussed earlier in this study, some particular forms of these three structural types can be observed in some natural pearls, and thus greater care is needed in their interpretation. This illustrates that the distinction between NBC and natural pearls is not always straightforward, and therefore different identification opinions or inconclusive calls may result in certain cases. The results obtained from different analytical methods may also influence the identification results. Factors such as instrument quality and resolution, the operator's experience, and even the level of care taken during analysis can combine to further hinder identification. In challenging cases, the use of $\mu-\mathrm{CT}$ is necessary to provide the best possible data for interpreting a pearl's structure. Lastly, only 86 P. maxima cultured pearl samples were examined in this study. Additional cultured pearl samples are necessary to gain an even greater understanding about the range of possible structures in cultured pearls and to benefit the identification process. The continued study of the internal structures of known cultured pearls provides dependable results that enhances GIA's reference collection database and can provide clients with greater peace of mind.
ABOUT THE AUTHORS

Mrs. Homkrajae is a senior staff gemologist at GIA in Carlsbad, California. Ms. Nilpetploy is a senior staff gemologist, Ms. Manustrong is a staff gemologist, Mr. Sturman is a consultant to GIA, Ms. Lawanwong is an analytics technician, and Mr. Kessrapong is a former analytics technician, all in GIA's Bangkok laboratory.

\section{ACKNOWLEDGMENTS}

The authors wish to extend their appreciation to Paspaley Pearling Company, Australia, for loaning the samples to GIA's Bangkok laboratory for this study and inviting GIA staff to visit Australia to retrieve the pearls in person. We also wish to thank Tom Moses and Kenneth Scarratt for their support and for making the trips to Paspaley possible. Sasithorn Engniwat's assistance in providing the macro images in all the tables is also greatly appreciated. Lastly, we would like to thank the peer reviewers for valuable and constructive comments that improved this article.

\section{REFERENCES}

Al-Alawi A., Ali Z., Rajab Z., Albedal F., Karampelas S. (2020) Saltwater cultured pearls from Pinctada radiata in Abu Dhabi (United Arab Emirates). Journal of Gemmology, Vol. 37, No. 2, pp. 164-179.

Cartier L.E., Krzemnicki M.S. (2013) New developments in cultured pearl production: Use of organic and baroque shell nuclei. Australian Gemmologist, Vol. 25, No. 1, pp. 6-13, https://www.ssef.ch/wp-content/uploads/2018/06/2013-Organic-baroque-shell-nuclei-Cartier-Krzemnicki-GAA.pdf

(2016) Golden South Sea cultured pearls: Cultivation steps \& gemmological investigations. The Journal of the Gemmological Association of Hong Kong, Vol. 37, pp. 16-21, http://www.gahk.org/journal/2016/a5.pdf
Cartier L.E., Krzemnicki M.S., Rere J. (2013) Pearl or gemstone? Galatea pearls: A 'new' pearl product from French Polynesia. 33rd International Gemmological Conference, Hanoi, Vietnam, pp. 64-66.

CIBJO, The World Jewellery Confederation (2020) The Pearl Book. CIBJO Pearl Commission, 79 pp.

Crichton R. (2019) Biological Inorganic Chemistry: A New Introduction to Molecular Structure and Function, 3rd ed. Université Catholique de Louvain, Belgium, https://doi.org/10.1016/C20160-01804-1

Gervis M.H., Sims N.A. (1992) The Biology and Culture of Pearl Oysters (Bivalvia: Pteriidae). ICLARM Studies and Reviews 21, Manila, Philippines, 49 pp. 
Hänni H.A. (2006) A short review of the use of 'keshi' as a term to describe pearls. Journal of Gemmology, Vol. 30, No. 1/2, pp. 51-58.

(2012) Natural pearls and cultured pearls: A basic concept and its variations. Australian Gemmologist, Vol. 24, No. 11, pp. 258-266.

Hänni H.A., Krzemnicki M.S., Cartier L. (2010) Appearance of new bead material in cultured pearls. Journal of Gemmology, Vol. 32, No. 1, pp. 31-37.

Homkrajae A., Manustrong A., Nilpetploy N., Sturman N., Lawanwong K., Kessrapong P. (2021) Internal structures of known Pinctada maxima pearls: Natural pearls from wild marine mollusks. $G \uplus G$, Vol. 57, No. 1, pp. 2-21, http://dx.doi.org/10.5741/GEMS.57.1.2

Hsu T., Zhou C., Homkrajae A., Ho J.W.Y., Yazawa E., Padua P. (2016) Freshwater pearling in Tennessee. GIA Research News, October 7, https://www.gia.edu/gia-news-research/freshwaterpearling-tennessee

Karampelas S., Al-Alawi A.T., Al-Attawi A., Scarratt K. (2017) Natural pearls found from Pinctada radiata in the Kingdom of Bahrain: Characteristic structures, comparison and identification. 35th International Gemmological Conference, Windhoek, Namibia, pp. 103-104.

Kessrapong P., Lawanwong K. (2020) Atypical bead cultured Pinctada maxima pearls nucleated with freshwater non-bead cultured pearls. GIA Research News, April 6, https://www.gia.edu/doc/Atypical-Bead-Cultured-Nucleatedwith-Freshwater-NBCP.pdf

Krzemnicki M., Friess D., Chalus P., Hänni H.A., Karampelas S. (2010) X-ray computed microtomography: Distinguishing natural pearls from beaded and non-beaded cultured pearls. $G \uplus G$, Vol. 46, No. 2, pp. 128-134, http://dx.doi.org/10.5741/GEMS.46.2.128

Krzemnicki M.S., Müller, Hänni H.A., Gut H.-P., Düggelin M. (2011) Tokki pearls: Additional cultured pearls formed during pearl cultivation: External and internal structures. 32nd International Gemmological Conference, Interlaken, Switzerland, https://www.ssef.ch/wp-content/uploads/2018/01/SSEF_Tokki_pearls.pdf

Landman N.H., Mikkelsen P.M., Bieler R., Bronson B. (2001) Pearls: A Natural History. Harry N. Abrams, Inc., New York, $232 \mathrm{pp}$.

Manustrong A. (2018) Gems News International: Very small akoya cultured pearls. $G \uplus G$, Vol. 54, No. 1, pp. 103-105, https://www.gia.edu/gems-gemology/spring-2018-gemnewsvery-small-akoya-cultured-pearls

Manustrong A., Lawanwong K. (2020) Lab Notes: Saltwater bead cultured pearl with laminated nucleus. $G \uplus G$, Vol. 56, No. 1, pp. 138-139, https://www.gia.edu/gems-gemology/spring-2020labnotes-cultured-pearl-laminated-nucleus

Manustrong A., Kessrapong P., Lawanwong K., Nilpetploy N., Homkrajae A. (2019) Known non-nacreous non-bead cultured pearls and similar unknown pearls of likely cultured origin from Pinctada maxima. GIA Research News, September 4, https://www.gia.edu/gia-news-research/known-non-nacreousnon-bead-cultured-pearls

Marie B., Joubert C., Tayalé A., Zanella-Cléon I., Belliard C., Piquemal D., Cochennec-Laureau N., Marin F., Gueguen Y., Montagnani C. (2012) Different secretory repertoires control the biomineralization processes of prism and nacre deposition of the pearl oyster shell. Proceedings of the National Academy of Sciences, Vol. 109, No. 51, pp. 20986-20991, http://dx.doi.org/10.1073/pnas.1210552109

Nilpetploy N., Lawanwong K., Kessrapong P. (2018a) Non-bead cultured pearls from Pinctada margaritifera. GIA Research News, April 27, https://www.gia.edu/ongoing-research/nonbead-cultured-pearls-from-pinctada-margaritifera

- $(2018 \mathrm{~b})$ The gemological characteristics of Pipi pearls re- portedly from Pinctada maculata. GÆ G, Vol. 54, No. 4, pp. 418-427, http://dx.doi.org/10.5741/GEMS.54.4.418

Otter L.M., Wehrmeister U., Enzmann F., Wolf M., Jacob D.E. (2014) A look inside a remarkably large beaded South Sea cultured pearl. Ge G, Vol. 50, No. 1, pp. 58-62, http://dx.doi.org/10.5741/GEMS.50.1.58

Otter L.M., Oluwatoosin B.A., Huong L.T., Häger T., Jacob D.E. (2017) Akoya cultured pearl farming in eastern Australia. $G \oplus G$, Vol. 53 , No. 4, pp. 423-437, http://dx.doi.org/10.5741/GEMS.53.4.423

Scarratt K. (2019) A recent expedition to acquire \& characterise natural pearls from Australian Pinctada [video presentation]. The Pearl Symposium, November 21, https://www.youtube.com/watch? v=0gu3467SaBY

Scarratt K., Moses T.M., Akamatsu S. (2000) Characteristics of nuclei in Chinese freshwater cultured pearls. $G \uplus G$, Vol. 36, No. 3, pp. 98-109, http://dx.doi.org/10.5741/GEMS.36.2.98

Scarratt K., Bracher P., Bracher M., Attawi A., Safar A., Saeseaw S., Homkrajae A., Sturman N. (2012) Natural pearls from Australian Pinctada maxima. Ge G, Vol. 48, No. 4, pp. 236-261, http://dx.doi.org/10.5741/GEMS.48.4.236

Scarratt K., Sturman N., Tawfeeq A., Bracher P., Bracher M., Homkrajae A., Manustrong A., Somsa-ard N., Zhou C. (2017) Atypical "beading" in the production of cultured pearls from Australian Pinctada maxima. GIA Research News, https://www.gia.edu/gia-news-research/atypical-beading-production-cultured-pearls-australian-pinctada-maxima

Snow M. (1999) Bironite: A new source of nuclei. Pearl Oyster Bulletin, No. 13, pp. 19-21.

Southgate P.C., Lucas I.S (2008) The Pearl Oyster. Elsevier, Oxford, $574 \mathrm{pp}$.

Strack E. (2006) Pearls. Rühle-Diebener-Verlag, Stuttgart, Germany.

Sturman N. (2009) The microradiographic structures of non-bead cultured pearls. GIA Research News, https://www.gia.edu/gianews-research-NR112009

Sturman N., Al-Attawi A. (2006) The "keshi" pearl issue. GÆG, Vol. 42, No. 3, p. 142.

Sturman N., Homkrajae A., Manustrong A., Somsa-ard N. (2014) Observations on pearls reportedly from the Pinnidae family (Pen pearls). G巴 G, Vol. 50, No. 3, pp. 202-215, http://dx.doi.org/10.5741/GEMS.50.3.202

Sturman N., Bergman J., Poli J., Homkrajae A., Manustrong A., Somsa-ard N. (2016) Bead-cultured and non-bead-cultured pearls from Lombok, Indonesia. GÆ G, Vol. 52, No. 3, pp. 288 297, http://dx.doi.org/10.5741/GEMS.52.3.288

Sturman N., Manustrong A., Lawanwong K., Kessrapong P., Somsa-ard N., Homkrajae A. (2017) "Golden" Pinctada maxima non-bead cultured pearls with an emphasis on their internal structures. Proceedings of the 35th International Gemmological Conference, Windhoek, Namibia, pp. 100-102.

Sturman N., Otter L.M., Homkrajae A., Manustrong A., Nilpetploy N., Lawanwong K., Kessrapong P., Jochum K.P., Stoll B., Götz H., Jacob D.E. (2019) A pearl identification challenge. $G \uplus G$, Vol. 55, No. 2, pp. 229-243, http://dx.doi.org/10.5741/GEMS.55.2.229

Sturman N., Lawanwong K., Kitdee N., Chodhry D. (2020) Vietnam: Shell nuclei, pearl hatcheries, and pearl farming. $G \uplus G$, Vol. 56, No. 3, pp. 402-415, http://dx.doi.org/10.5741/GEMS.56.3.402

Wehrmeister U., Goetz H., Jacob D.E., Soldati A., Duschner W., Xu H., Hofmeister W. (2008) Visualization of the internal struc tures of cultured pearls by computerized X-ray microtomography. Journal of Gemmology, Vol. 31, No. 1/2, pp. 15-21.

Western Australia Department of Fisheries (2016) Pearl Oyster Fishery: Western Australian silver-lipped pearl oyster (Pinctada maxima) resource harvest strategy 2016-2021, Version 1.0. Fisheries Management Paper No. 276, http://www.fish.wa.gov.au/Documents/management_papers/f mp276.pdf 